\title{
2000 MRS Spring Meeting Leads Materials Research into the New Millennium
}

Nanotechnology received increased focus in several symposia at the 2000 Materials Research Society Spring Meeting held in San Francisco on April 24-28. For the second year, the meeting was held at two hotels, the Marriott and the Argent. The core of the meeting consisted of 34 technical symposia covering a wide range of materials research topics. In addition, the meeting included poster sessions; an exhibit; five tutorials; special presentations including the plenary talk, the Outstanding Young Investigator talk, and the graduate student award finalists talks; and several other activities. The meeting chairs were Anna C. Balazs (Univ. of Pittsburgh), Robert Q. Hwang (SNL), Kevin S. Jones (Univ. of Florida), and Frances M. Ross (IBM T.J. Watson Research Center). Over 2,900 people attended the Meeting and a little over 2,000 papers were presented.

\section{Technical Symposia}

Nanotechnology

In one of four special U.S. government presentations, M. Roco (NSF), chair of the NSTC Interagency Working Group on Nanoscience, Engineering, and Technology, said that U.S. government agencies are following a national initiative in placing nanotechnology at the top of their scientific research priorities. He said that current challenges in manufacturing at the nanoscale include creating tailored structures at the 0.1-100 nm range, combining top-down and bottom-up approaches, and integrating along scales with larger systems.

For the first time, the MRS Meeting hosted Symposium EE on Nanostructures in Polymers. The main theme showed how researchers might exploit the natural length scales of polymeric materials to create heterophase structures of nanoscale dimensions. Among the highlights, M.F. Rubner (MIT) demonstrated a novel layer-by-layer deposition strategy for producing nanoscopic, multilayered heterostructures containing metal nanoparticles and L. Leibler (Elf Atochem) described a method to exploit the inherent self-assembling properties of triblock copolymers to produce supertough semicrystalline materials.

In Symposium CC, the synthesis, char- acterization, and properties of organic/ inorganic materials were covered. Within this context, B. Lebeau (CNRS, Mulhouse) and F. Schuth (MPI, Mulheim) discussed the funtionalization of nanopores to produce materials with photonic applications. J. Liu (PNNL) gave a talk titled "Multifunctionalized Hybrid Ceramic Materials Show Potentials for Selective Adsorption, Efficient Catalysis, and Controlled Release." Nature is abundant with multifunctional materials that show extremely high efficiency and selectivity. In addition, such materials are highly intelligent so that the activity and accessibility are regulated based on the functional need of the system. One good example is an enzyme. Novel functional hybrid materials have now been created that mimic some of the functions of the biological counterpart. Instead of relying on one or two kinds of functional groups, multiple functional groups are attached to an ordered nanoporous material. This material shows enzyme-like catalytic activity. In addition, a molecular imprinting technique is used to control the spatial arrangement of the functional groups as well as the shape of the microporosity. This approach produced hierarchical nanoporous materials with precise shape and size selectivity. Furthermore, incorporating smart poly-

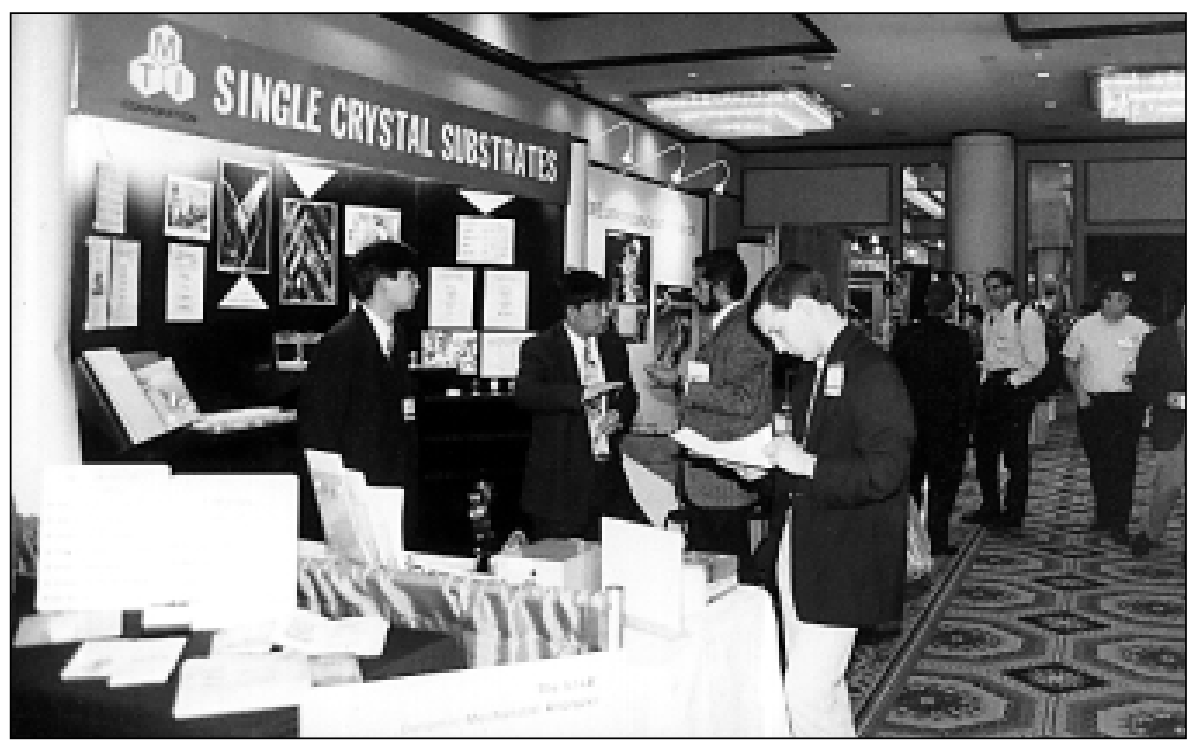

Meeting attendees take the opportunity to visit the exhibitors. 
mers into the hybrid nanoporous materials allows the accessibility to the pore channels to be regulated by a change in temperature. Temperature-controlled drug release has been demonstrated. This class of hybrid materials is believed to have potential for more efficient catalysis in chemical industry, for highly selective adsorption in environmental remediation, and for controlled release in biomedical applications.

Also in Symposium CC, C.H.A. Rentrop (TNO-TPD, The Netherlands) gave a presentation on "Multifunctional Nanocomposite Coatings and Bulk Materials." The homogeneous dispersion in coating systems and bulk materials of clay platelets modified with organic molecules that contain two or more charged functional groups is called the Planomers ${ }^{\circledR}$ concept. This modification results in the formation of clay platelets "coated" with charges, which are mutually repulsive, that can be readily dispersed. The resulting nanocomposite coatings show high transparency at a layer thickness ranging from 10 to $40 \mathrm{~mm}$, which has been determined from TEM measurements of the coatings on polycarbonate and glass. These transparent coatings are highly resistant to the passage of water vapor. The concept has been extended to the addition of colored dyes (Planocolors) such as methylene blue. The colored nanocomposite coatings have considerably improved UV stability compared with

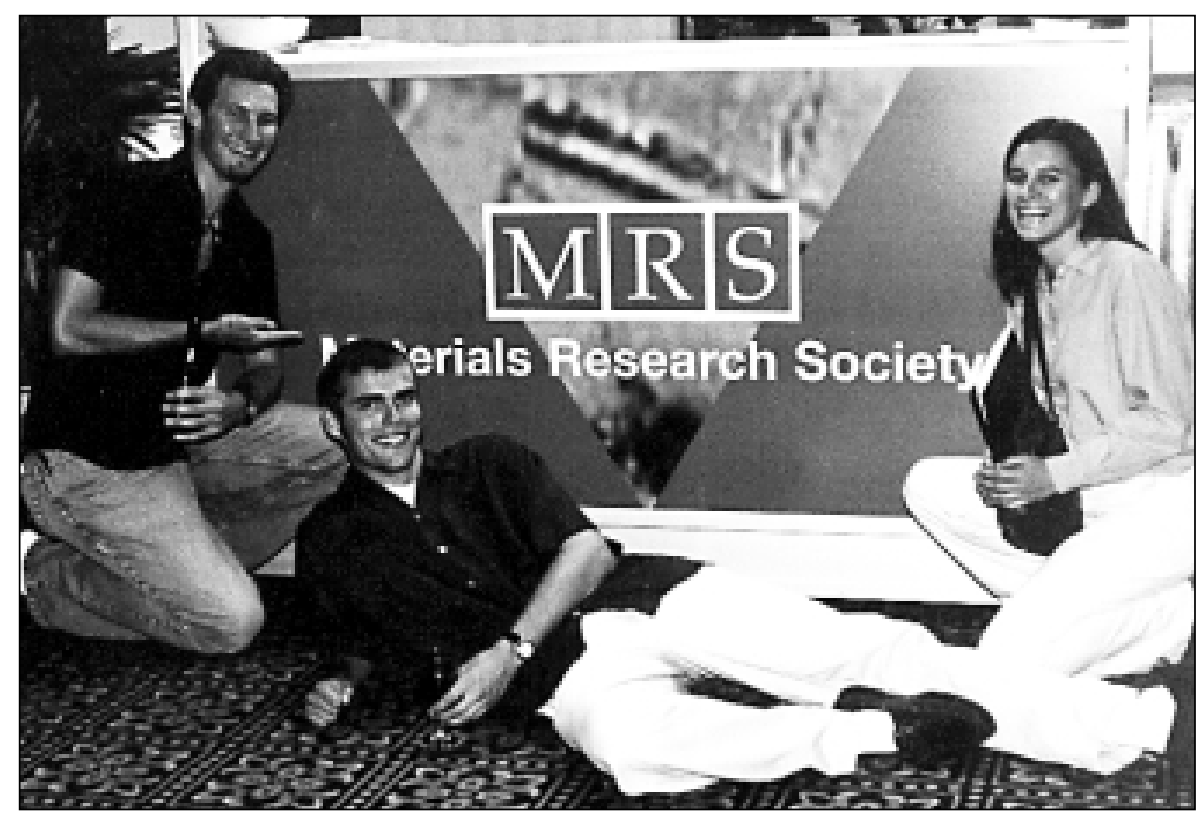

MRS Meeting attendees step outside the Student Mixer to pose for their "favorite" Societyperhaps seeking a new research project in modeling.

conventional organic coatings, and also are resistant to solvents.

The topic of nanotechnology also highlighted several other symposia. S.Y. Chou (Princeton Univ.) gave a talk in Symposium F on QMD as a new paradigm for magnetic storage. In particular he de- scribed nanoimprint lithography as an effective low-cost technique to pattern material. He also discussed LISA, a potential method to fabricate QMD masks. E. Mazur (Harvard Univ.), in Symposium J, described the formation of $3 \mathrm{D}$ arrays in glass using nonlinear inter-

\section{ACRONYM KEY}

\author{
1D: one dimensional \\ 2D: two dimensional \\ 3D: three dimensional \\ AFM: atomic force microscopy \\ AFOSR: Air Force Office of Scientific Research \\ AFRL: U.S. Air Force Research Laboratory \\ ALD: atomic layer deposition \\ ANL: Argonne National Laboratory \\ ARO: Army Research Office \\ BJT: bipolar junction transistors \\ BST: barium strontium titanate \\ CMOS: complementary metal oxide semiconductor \\ CMP: chemical-mechanical polishing \\ CMR: colossal magnetoresistance \\ CNRS: Centre National de la Recherche Scientifique \\ CVD: chemical vapor deposition \\ DOE: Department of Energy \\ EA: electroabsorption \\ ECD: Energy Conversion Devices \\ EDMR: electrically detected magnetic resonance \\ FEA: field emitter array \\ FED: field emission display \\ FET: field-effect transistor \\ GE: General Electric \\ GMR: giant magnetoresistance \\ HBT: heterojunction bipolar transistors \\ HEMT: high-electron-mobility transistor \\ IMRE: Institute of Materials Research and Engineering
}

$\begin{array}{ll}\text { LBNL: Lawrence Berkeley National Laboratory } & \text { ORNL: Oak Ridge National Laboratory } \\ \text { LCVD: laser chemical vapor deposition } & \text { OSTP: Office of Science and Technology Policy } \\ \text { LED: light-emitting diode } & \text { PDS: photothermal deflection spectroscopy } \\ \text { LEEM: low energy electron microscopy } & \text { PET: polyethylene terephthalate } \\ \text { LENS: laser engineered net shaping } & \text { PLD: pulsed laser deposition } \\ \text { LISA: lithographically induced self-assembly } & \text { PLED: polymer light-emitting diode } \\ \text { LLNL: Lawrence Livermore National Laboratory } & \text { PNNL: Pacific Northwest National Laboratory } \\ \text { MAPLE DW: matrix assisted pulsed laser evaporation } & \text { QMD: quantized magnetic disks } \\ \text { direct write } & \text { RAM: random-access memory } \\ \text { MBE: molecular beam epitaxy } & \text { rf: radio frequency } \\ \text { MCNC: Microelectronics Center of North Carolina } & \text { SCM: scanning capacitance microscopy } \\ \text { MEMS: microelectromechanical systems } & \text { SDT: spin-dependent tunneling } \\ \text { MFM: magnetic force microscopy } & \text { SH-MOKE: second-harmonic magneto-optic Kerr } \\ \text { MICE: mesoscopic integrated conformal electronics } & \text { effect } \\ \text { MIP: molecular imprint polymer } & \text { SNL: Sandia National Laboratories } \\ \text { MIT: Massachusetts Institute of Technology } & \text { SOI: silicon-on-insulator } \\ \text { MOSFET: metal oxide semiconductor field-effect tran- } & \text { SSRM: scanning spreading resistance microscopy } \\ \text { sistor } & \text { STM: scanning transmission microscopy } \\ \text { MSE: materials science and engineering } & \text { TCO: transparent conducting oxide } \\ \text { NASA: National Aeronautics and Space Administration } & \text { TEM: transmission electron microscope } \\ \text { NIST: National Institute of Standards and Technology } & \text { TFT: thin film transistor } \\ \text { NMR: nuclear magnetic resonance } & \text { TI: Texas Instruments } \\ \text { NREL: National Renewable Energy Laboratory } & \text { UCLA: University of California-Los Angeles } \\ \text { NRL: Naval Research Laboratory } & \text { UHV: ultrahigh vacuum } \\ \text { NSF: National Science Foundation } & \text { UMIST: University of Science and Technology in } \\ \text { NSTC: National Science and Technology Council } & \text { Manchester } \\ \text { OLED: organic light-emitting diode } & \text { UV: ultraviolet } \\ \text { ONR: Office of Naval Research } & \text { XRD: x-ray diffraction } \\ & \end{array}$

LBNL: Lawrence Berkeley National Laboratory

LCVD: laser chemical vapor deposition

.

LENS: laser engineered net shaping

LISA: lithographically induced self-assembly

LLNL: Lawrence Livermore National Laboratory

DW: matrix assisted pulsed laser evaporation

MBE: molecular beam epitaxy

MCNC: Microelectronics Center of North Carolina

MIP: molecular imprint polymer

MIT: Massachusetts Institute of Technology

metal oxide semiconductor field-effect tran-

MSE: materials science and engineering

NASA: National Aeronautics and Space Administration

NMR: nuclear magnetic resonance

NREL: National Renewable Energy Laboratory

L: Naval Research Laboratory

NSTC: National Science and Technology Council

ONR: Office of Naval Research

\author{
ORNL: Oak Ridge National Laboratory \\ OSTP: Office of Science and Technology Policy \\ PET: polyethylene terephthalate \\ PNNL: Pacific Northwest National Laboratory \\ : quantized magnetic disks \\ rf: radio frequency \\ SCM: scanning capacitance microscopy \\ SDT: spin-dependent tunneling \\ effect
SNL. Sandia National Laboratorie \\ SOI: silicon-on-insulator \\ : scanning spreading resist \\ TCO: transparent conducting oxide \\ TEM: transmission electron microscope \\ UCLA: University of California—Los Angeles \\ UHV: ultrahigh vacuum \\ UV: ultraviolet
XRD: $x$-ray diffraction
}


actions at short pulse widths. Formation of carbon nanotubes by laser ablation was discussed in presentations by Oak Ridge National Laboratory researchers. J.M. Kim (Samsung Corp.), in Symposia Q and $\mathrm{R}$, described carbon nanotube utilization in a large area, full-color FED. And T.C. Harman (MIT) in Symposium Z presented results on quantum dot nanostructures of $\mathrm{PbTe}$ materials.

\section{Direct-Write, Milli- Submilli- Wave Technology, Materials and Disasters, and MSE Education}

The Spring Meeting hosted several other topics for the first time, and incorporated the Materials Education Workshop, which is traditionally held at the Fall Meeting. The topic of materials issues in analyzing, predicting, and preventing disasters (Symposium GG) brought together experts from various areas. Topics included aerospace fractures, heart valve failures, origin and prevention of fires, radiation damage, creep fracture, collapse of buildings, and natural

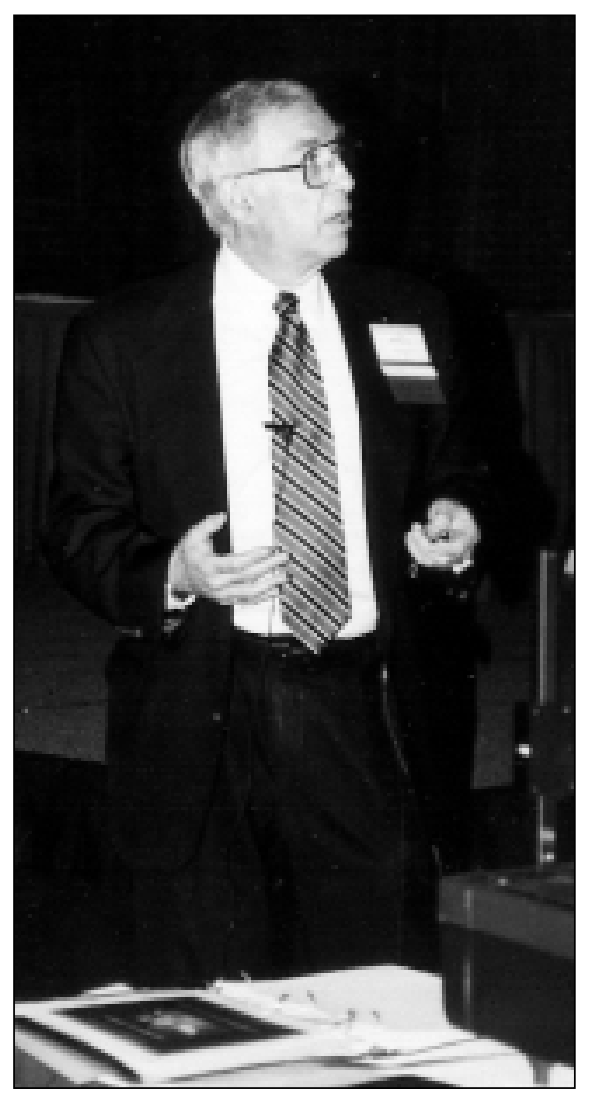

Arthur Bienenstock (Associate Director for Science, U.S. Office of Science and Technology Policy) presented the plenary talk on "Seeking Balance in the Federal Research Budget." disasters. A number of speakers identified specific materials problems that could help prevent most of the disasters described. R.L. Schwoebel discussed his investigation of the explosion on the U.S. Naval Ship, the USS Iowa. An explosion in one of the warship's 16-in. guns killed 37 crewmen in 1989. A Naval investigation concluded that this was not an accident, but was caused deliberately by a crewman, who was also killed in the incident. This was based on the Navy's finding of foreign materials from a hypothetical explosive device including $\mathrm{Ca}$ and $\mathrm{Cl}$ (HTH, similar to bleach), two glycols (brake fluids), iron fibers, and a PET fragment that supposedly came from a plastic container. Based on this evidence, the Navy concluded that the explosion was caused by a simple device built by the crewman. Schwoebel's group was then called in to investigate this evidence independently. His group found that $\mathrm{Ca}$ and $\mathrm{Cl}$ were present all over the area, that the glycols originated from "Break Free," a fluid used to clean and lubricate, iron fibers were present in areas not exposed to the explosion, and the polymer PET film fragment came from a bore brush used for cleaning.

The group's investigation turned to the powder bag configuration. The powder bags contain the propellent pellets stacked with a trim layer on the top. At the bottom of each bag is a powder pad which is used for ignition. The group was able to demonstrate that due to excessive pressure in the stacked powder bags, the powder pads ignited and the trim layers were responsible for the explosion. Overall, the incident was attributed to inexperienced crewmen, and poor training, as well as frequent turnover of crew. Schwoebel has published a book on this subject titled Explosion Aboard the Iowa.

In the same session, R. Gibala (Univ. of Michigan) presented his experience on "Forensics of Fire Exposed Materials." Building fires have been blamed on fluorescent lighting systems, he said, in particular the ballast components wherein the transformer assembly steps up the 110-120 line voltage to 200-220 V for efficient operation. Gibala's team has investigated a number of these fires and found only one case in which the ballast component could be blamed. Gibala said that growth of copper sulfide whiskers on copper transformer wires provided unambiguous evidence in cases in which the ballasts were blameless. He described the materials connection in such investigations which include various materials characterization techniques. He also discussed several associated legal issues.
E. Bouchaud (CEA Saclay) discussed damage and fracture in complex microstructures. The morphology of fracture surfaces has been shown to exhibit universal characteristics and a statistical study of fracture surfaces was performed. Numerical simulations of damage and fracture were conducted. Bouchaud said this should lead to a better understanding of damage and fracture mechanisms at the microstructural scale, and help researchers design tough materials.

Symposium AA covered the use of Millimeter/Submillimeter Wave Technology as a tool for versatile materials research. P.P. Woskov (MIT) and S. K. Sundaram (PNL) described the application of millimeter wave technology to diagnose high temperature processes under harsh environments using robust waveguides and novel designs. J.G. Fleming (SNL) and T.W. Crowe (Univ. of Virginia) elaborated on fabrication and characterization of different diodes for application in millimeter/submillimeter wave technology. Advances in circuit design, architecture, and manufacture have recently combined to provide a realistic path forward for the manufacture of low-cost, high-performance terahertz components and systems, as suggested by C.M. Mann (Rutherford Appleton Lab, UK) in his talk. It is now possible to provide solid-state electronic components in the millimeter, sub-millimeter, and $\mathrm{THz}$ regions of the electronic spectrum. Waveguide devices are gaining interest because new micromachining techniques have resulted in cost reductions. Mann described a technique that has been developed that allows the complete component to be formed on a silicon wafer, thereby reducing the fabrication costs by about 3 orders of magnitude. Planar or integrated circuitry mounted in waveguides has now demonstrated stateof-the-art performance to $2.5 \mathrm{THz}$. Increased detector bandwidth and sensitivity will allow more complex measurements to be made. System complexity can now be increased and can be tailored to specific measurement criteria.

Symposium V on Materials for DirectWrite Technologies emphasized new materials approaches based on the directwrite technique, including plasma spray, laser particle guidance, laser CVD, micropen, ink jet, e-beam, focused ion beam, and various novel liquid or droplet microdispensing techniques. A common theme running through these techniques was the requirement for high-quality starting materials.

Continuing the series of symposia on materials science and engineering education, Symposium $\mathrm{HH}$ addressed a number 


\section{MRS Presents Graduate Student Awards}

The MRS Graduate Student Awards were presented by MRS Treasurer Merrilea J. Mayo (Pennsylvania State Univ.) on Monday evening, April 24, during the 2000 MRS Spring Meeting in San Francisco.

The Gold Award recipients are (back row, left to right): Kevin J. Davis, Georgia Institute of Technology (M9.5: Resolving the Control of Magnesium on Calcite Growth: Thermodynamic and Kinetic Consequences of Impurity Incorporation for Biomineral Formation); J. Axel van de Walle, MIT (O6.3: Automating Phase Diagram Calculations); Christopher Caylor, University of California-Berkeley (Z1.3: Pulsed Laser Deposition of Thin-Film Skutterudite Thermoelectrics); (front row, left to right): Ana Claudia Arias, Cavendish Laboratory, United Kingdom (S8.5: Control and Characterization of Photoresponsive Polyfluorene Blend Morphology); Nicholas A. Melosh, University of Santa Barbara-Berkeley (CC3.8: Silica-Block Copolymer Composites with Macroscopic Ordering Domains); and An Steegen, IMEC, Belgium (C6.4: Stress Build-Up During the NiSilicidation in and around Narrow NiSi Lines).

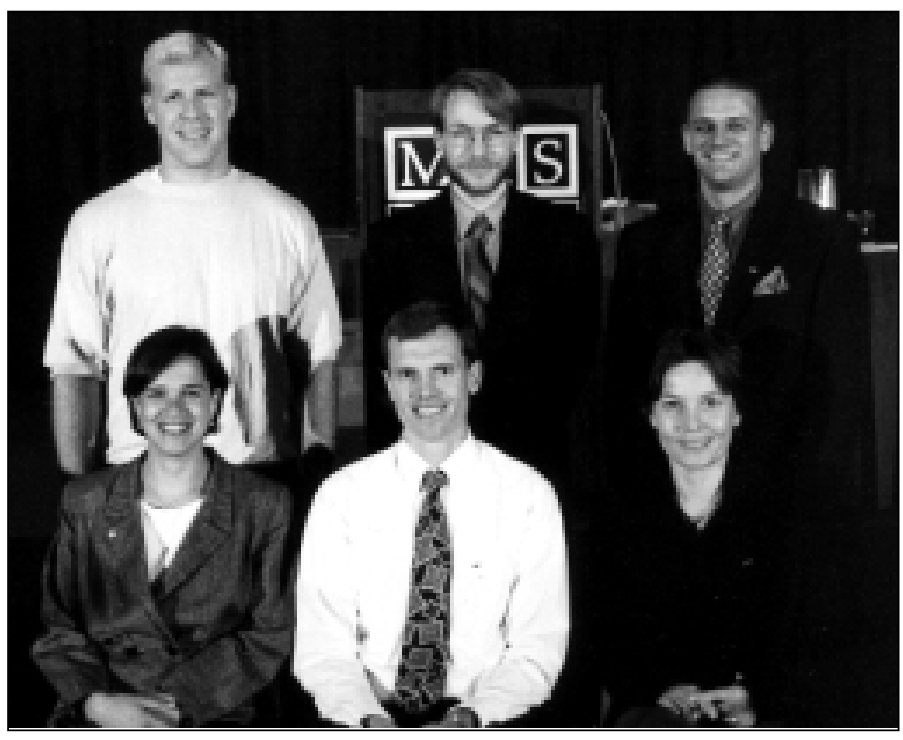

The Silver Award recipients are (back row, left to right): Ant Ural, Stanford University (B4.11: What Does Silicon Self-Diffusion Tell Us About Ultra-Shallow Junctions?); Hongyou Fan, University of New Mexico (CC6.33: Rapid Prototyping of Patterned Organic-Inorganic Multifunctional Nanostructures; CC6.41: OrganicInorganic Multifunctional MesoStructured Silica Films; V3.9/Y3.9: Rapid Fabrication of Patterned Functional Nanostructures via Direct Writing and Printing); Stephan Heck, National Renewable Energy Laboratory (A3.2: Slow Defect Increase during LowIntensity Pulsed Illumination of Hydrogenated Amorphous Silicon: New Results); Marian M.

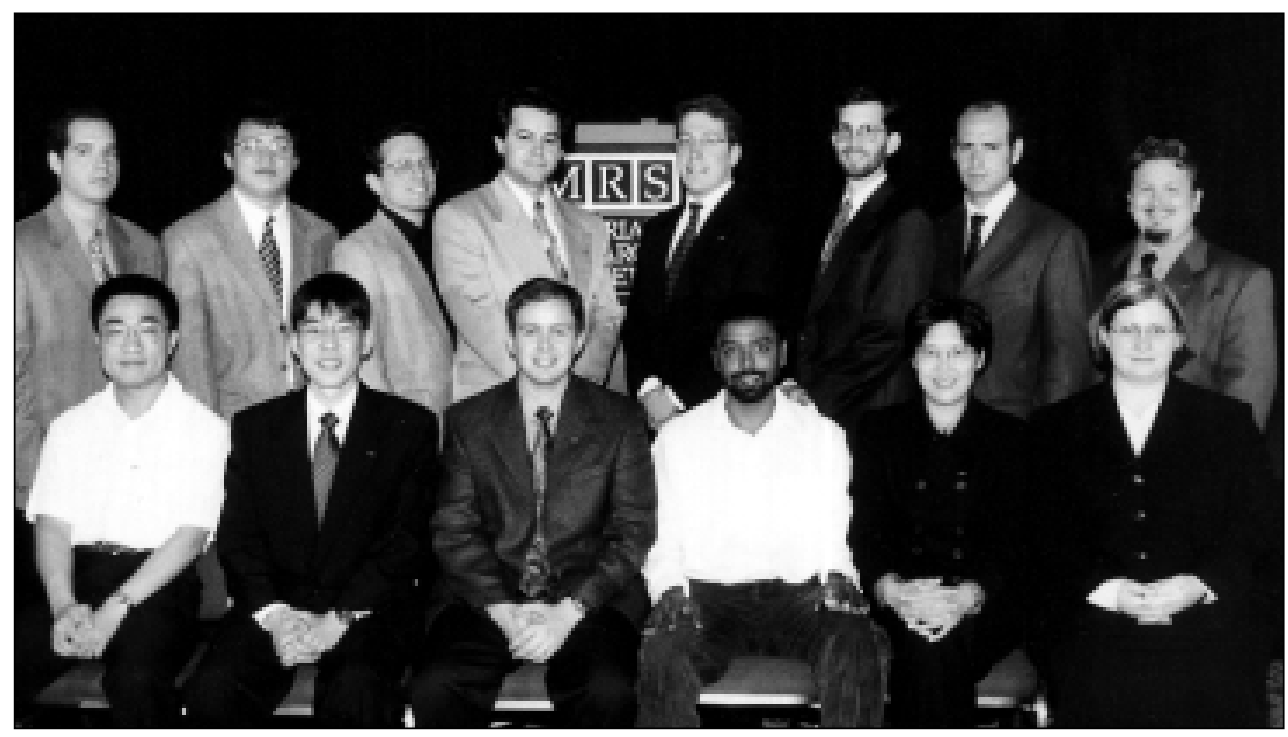

Manciu, State University of New

York-Buffalo (BB3.4: Backscattering of Nonlinear Acoustic Impulses from Buried Inclusions in Granular Beds); Steven B. Nicoll, University of California-Berkeley (DD1.7: Enhanced Attachment and Proliferation of Human Neonatal Dermal Fibroblasts on Expanded PTFE Substrates Modified with P-15, a Synthetic Peptide Analogue of Collagen); Lawrence F. Schloss, Lawrence Berkeley National Laboratory and University of California-Berkeley (U3.3: Pyroelectric Coefficient Optimization through Grain-Size Control in (Ba,Sr) $\mathrm{TiO}_{3}$ Thin Films); Paolo Samori, Humboldt University, Berlin (EE7.4: Controlling the SelfAssembly of a Rigid-Rod Polymer at Surfaces; M8.2: Thermodynamics of the Macromolecular Physisorption at the SolidLiquid Interface; S6.11: Epitaxial Growth of Hexabenzocoronene Ultra-Thin Films from Solution); and Paul M. Voyles, University of Illinois-Urbana Champaign (A2.4: Medium-Range Order in Hydrogenated Amorphous Silicon Measured by Fluctuation Microscopy); (front row, left to right): Yangting Zhang,

University of Texas-El Paso (K4.6: Stability of Ensembles of $\mathrm{Ge} / \mathrm{Si}(100)$ Coherent Islands); Hiroshi Yanagi, Tokyo Institute of Technology, Japan (U6.6: Transparent $p$ - and $n$-Type Conductive Oxides with Delafossite Structure); David M. Longo, University of Virginia (V1.2: Direct Focused Ion-Beam Writing of Printheads for Pattern Transfer Utilizing Microcontact Printing); Ganesh K. Ramachandran, Arizona State University (Z13.2: Synthesis, Structure, and Thermopower Characteristics of Some (Si-Ge)Based Clathrate Structures; Z8.3: Lattice Dynamics Study of Anisotropic Heat Conduction in Superlattices); Eva Lai, Johns Hopkins University (DD2.6: Unraveling DNA Complexation Processes by Time-Resolved Multi-Angle Light Scattering); and Jennifer Gerbi, Coordinated Science Laboratories and University of Illinois-Urbana-Champaign (A5.3: Microstructural Control of Thin-Film Si Using Low-Energy, High-Flux Ions in Reactive Magnetron Sputter Deposition). 
of key issues including undergraduate education. One of the highlights was a talk by Nobel Laureate L.M. Lederman (Fermi National Lab) - in a joint session with Symposium $X$-on improving high school science education by reversing the normal biology, chemistry, and physics learning sequence. Several talks addressed $\mathrm{K}-12$ programs. W.E. Brower, Jr. (Marquette Univ.) described his department's pro- gram to keep inner-city school children at the 5th grade level on track for a career in engineering. The program specifically chose 5 th graders because they are identified as eager learners who have not yet

\section{UMRI Grant Recipients Present Posters}

Two years ago, MRS established a grant program for the Undergraduate Materials Research Initiative. Grant recipients gave poster presentations of their work as part of Symposium $\mathrm{HH}$ on education at the 2000 MRS Spring Meeting in San Francisco. Ilke Arslan (Univ. of Illinois at Chicago), a 2000 UMRI grant recipient, said that this was the first time she gave a poster presentation although she has previously given oral presentations at conferences. She said that the work she did on "Developing an Atomic-Scale Understanding of the StructureProperty Relationships of Dislocation Cores in GaN" (UMRI-17) has demonstrated screw dislocation, presenting a controversial result. At the poster session, Meeting attendees shared with Arslan their research results using other materials. She performed her research with postdoctoral students and an advisor at Illinois and an advisor at ORNL.

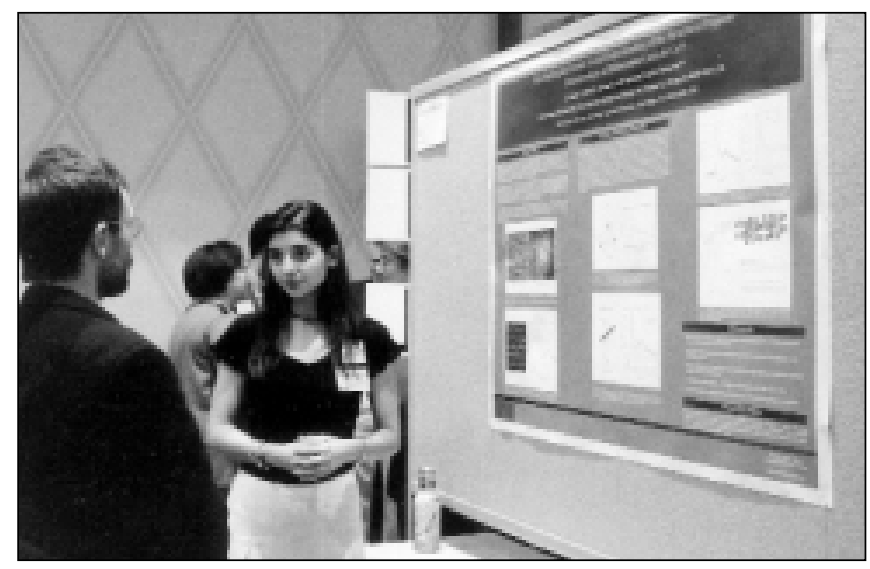

UMRI grant recipient Ilke Arslan presents her poster (UMRI-17) at the 2000 MRS Spring Meeting in San Francisco.

Joshua Goldberger (Ohio State Univ., 2000) presented his poster on "Synthesis and Characterization of New Vanadium Double Perovskites" (UMRI-42). He said that this is the first time he has applied for a research grant and that he had already planned to do the research project. He plans to continue his studies in materials-related chemistry in graduate school.

Rebecca Dylla (Univ. of Texas, UMRI-41) said that she had planned to do research for her undergraduate thesis but had not chosen a topic until after receiving the grant. She said that the UMRI grant has helped her with her project. Her "idealistic" advisor had helped her submit an ambitious proposal, but during the research she discovered several paths that would require some time before reaching results. She said that she feels like she has experienced intensive graduate-research work. She planned to find work after graduation, though she may decide later to return to school.

Cody Friesen and Joel Hayes (Arizona State Univ., UMRI-16) said that they learned collaboration from their project, from the collaborative effort involved in writing the proposal and throughout their work. This is the first time that they applied for a research grant. The students said that obtaining the grant

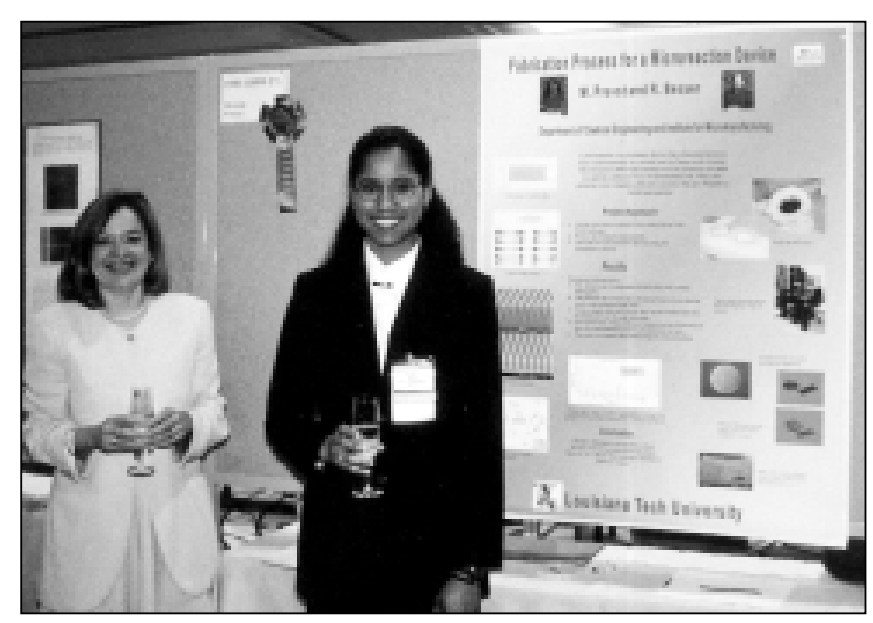

Meeting Chair Anna C. Balazs (above left) awards UMRI Poster Prizes to Michelle Prevot (UMRI-21) (above right) and to Matthew Wisnioski (UMRI-37) (below left).

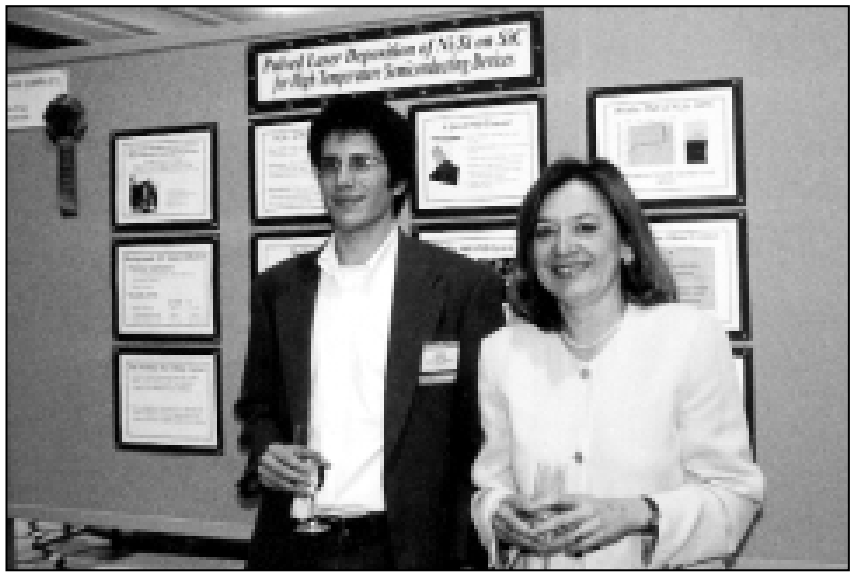

money up-front helped ease their work since unexpected expenses arose during the course of the work. The grant covered materials and equipment. Upon graduation from the Materials Department, both students plan to continue their studies in materials in graduate school.

During the Meeting, MRS awarded two poster prizes specifically for the UMRI presenters. Michelle Prevot (Louisiana Tech. Univ.), Fabrication Process for a Microreaction Device (UMRI-21) and Matthew Wisnioski (Johns Hopkins Univ.), PLD of $\mathrm{Ni}_{2} \mathrm{Si}$ on $\mathrm{SiC}$ for High-Temperature Semiconducting Devices (UMRI-37) received the awards. Prevot said she had spent many hours working in the laboratory on her project, late into the night. She will look for work after graduation, but wants to go to graduate school for research. However, she does not want to stay in chemical engineering. Wisnioski will attend Princeton University for graduate school in the history of science. While he is switching majors, he said that he enjoys research and will look for summer research work. 
chosen a science or math track and who have not experienced engineers as role models. He interacted with the audience as he demonstrated several experiments.

D. Hammer (MRSEC) described Maryland's MRSEC four-year program with Kettering Middle School. Through this program, students present their projects in a science fair for their families, peers, and community. In $\mathrm{K}-12$ education in a community setting, E. Werwa (Otterbein College) described the educational aspects of the MRS Materials MicroWorld project in several talks, including a joint session with Symposium X.

Several presenters described MSE college curriculums, including industrial influence and job trends, and in an unusual talk, J.C. Bravman (Stanford Univ.) addressed the balance of teaching and research in tenure decisions. He advised those seeking tenure to understand the expectations and tenure procedures of their institutions. He suggested they build courses around their research, involve students in their research, and to ensure that their work is known within their institution and among their key senior peers as well as within the materials research community.

\section{Computation and Modeling}

A panel discussion in Symposium $\mathrm{O}$ addressed the impact of materials computation. After introductory talks by panelists J. Williams (Ohio State Univ.), G.B. Olson (Northwestern Univ.), S.C. Glotzer (NIST), B.N. Harmon (Iowa State Univ. and Ames Lab.), M.S. Daw (Motorola), E. Wimmer (Materials Design S.A.R.L.) and D. Teeter (SNL), a dialogue ensued with the audience on issues such as knowing the customer, the importance of teaming with experimentalists and industry, and not overselling computational techniques. Before the panel discussion, Wimmer presented seven factors to success in computational materials science: (1) closing the link between experiment and simulation; (2), credible validation; (3) creative use of simulations; (4) effective teaching and training; (5) synergy between academic developers and software companies; (6) robust software environment; and (7) appreciation of real economic value. Teeter stressed that computational materials scientists need to know the customers' needs and customers need to be informed how computation can help them. For example, while materials scientists might be searching for materials harder than diamond, from a customers' perspective it may be more important to find a substitute material with properties very similar to diamond. In the area of education, the panelists and audience debated about the value of students using packaged software versus developing their own programs. The importance of focusing on the science was also brought out, rather than simply throwing computational power at a problem. While the impact of computational materials science is mostly on the macroscale, the expertise is still focused on the electronic and atomic scales. Bridging from here through the mesoscale to the continuum scale is one of the keys to useful application of these computational tools. Participants also said that when predicting properties of new materials, it is important not to oversell materials that do not really exist. In other words, local stability should be considered. In general, computation should be used to point to potentially interesting systems, but not considered an end in itself. The panel seemed to converge on the idea of the need to develop a vision for a national agenda on computational materials.

Presenters in Symposium P addressed significant challenges and opportunities that exist for bridging the range of time and size scales between atomistic simulations and continuum models for the macroscopic materials systems essential for industrial design and processing. Highlights of the Symposium included talks covering methodologies for mesoscale simulations such as the use of dynamic density functional theory to study the self-assembly of block polyelectrolyte molecules into robust polymer vesicles, and in the use of lattice chain models to study polymeric materials.

\section{Silicon Processing}

Symposium B on Si Front-End Processing-Physics and Technology of DopantDefect Interactions provided a session on dopant characterization in which 2D profiling techniques were discussed, including SCM, SSRM, and electron holography. As the requirements on junctions for sub$100-n m$ devices are 2D in nature, 2D profile measurements are apparently necessary for on-going development. Improving the relationship between junction depth and sheet resistance is also necessary for future device technologies, and various implant and annealing schemes were presented to accomplish this. Several speakers evaluated the implantation of alternative chemical species for defect engineering, including $\mathrm{C}, \mathrm{N}, \mathrm{F}, \mathrm{O}, \mathrm{Cl}, \mathrm{S}$, Se, and $\mathrm{Br}$. Also experimental data for the early phases of cluster formation were presented with information on modeling in

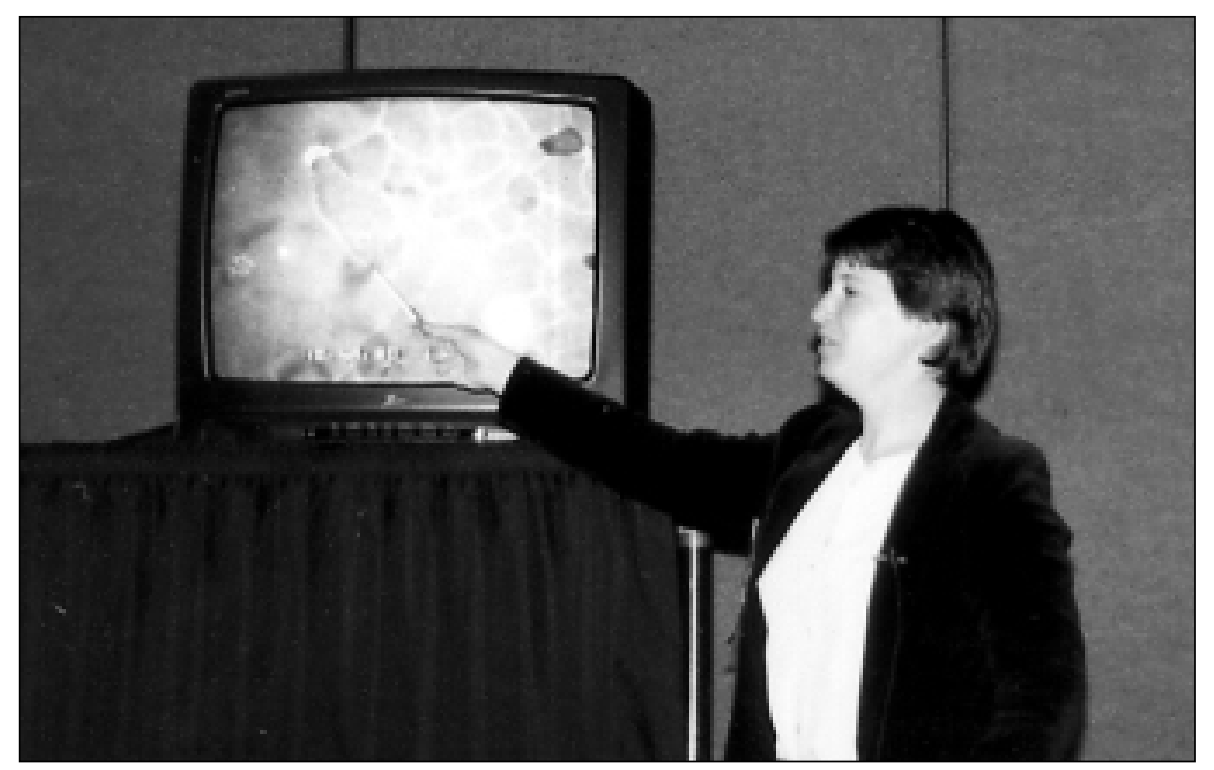

Frances M. Ross (IBM T.J . Watson Research Center) received the Outstanding Young Investigator award. In her talk, given as part of Symposium C, she described the ability to observe processes in real-time in an electron microscope that allows for the quantitative investigation of mechanisms and growth kinetics. Ross gave several examples of in situ electron microscopy observations of materials processes and behavior. She described the observation of the growth of self-assembled GeSi islands on Si (quantum dot structures) by using an in situ vapor deposition system. This allows for the measurement of the shape change and development of individual islands. Ross also discussed growth of self-assembled cobalt disilicide islands, which follows different kinetics. The growth data were fitted to appropriate models. She also studied silicon oxidation through the motion of Si steps during the reaction. 


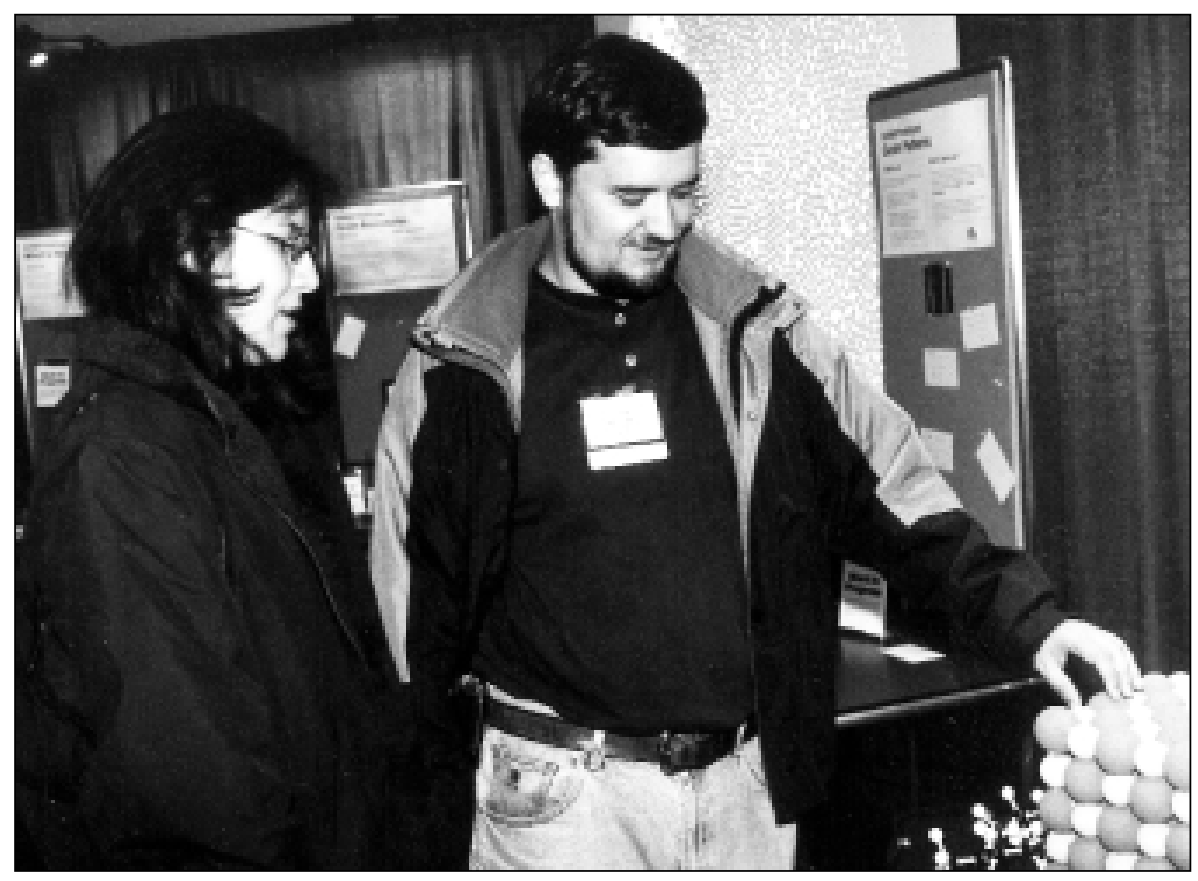

During breaks between technical sessions, Meeting attendees played in the MRS Materials MicroWorld area, where interactive display prototypes were on exhibit at the Spring Meeting.

order to enhance the understanding of dopant-defect interaction.

In Symposium D several talks addressed the relationship between materials properties and electrical performance of various high- $k$ dielectrics, with debate centering on the choice of the material. Several presentations also addressed various techniques being used to characterize porous materials including high-resolution $x$-ray reflectivity, small-angle neutron scattering, positron annihilation, and ellipsometric porosimetry. The Symposium was preceded by a tutorial on "Cu Interconnects: What are the Issues?" Held jointly with Symposia D, G, and H, the tutorial addressed the use of copper in integrated circuits in the metallization process as it presented a broad overview of various issues relevant to $\mathrm{Cu}$ interconnects. R. Rosenberg (IBM T.J. Watson Research Center) gave a detailed overview of the state-of-the-art of $\mathrm{Cu}$ metallization for high performance $\mathrm{Si}$ technology. He described the motivation for the use of $\mathrm{Cu}$, including comparisons with $\mathrm{Al}$, and the fabrication technologies involved. T. Moffat (NIST) covered the various issues associated with electrochemical deposition of $\mathrm{Cu}$. V. Brusic (Cabot Corp.) covered various aspects of corrosion of $\mathrm{Cu}$, which is crucial for $\mathrm{Cu}$ interconnects. Obviously, any Cu corrosion is unacceptable in the case of interconnects. Brusic described various tests conducted to characterize corrosion of $\mathrm{Cu}$, in particular relating to the use of chemical mechanical polishing. She also described strategies for prevention of $\mathrm{Cu}$ corrosion including kinetics and thermodynamic

Symposium A covered topics ranging from silicon thin film physics and chemistry to novel design and engineering. A focused session on the physics of amorphous and microcrystalline silicon solar cells was one of the highlights. Advanced characterization techniques were described wherein processes in solar cell materials could be probed in the actual device configuration. These included PDS to quantify solar energy loss mechanisms, EDMR to identify transport and recombination pathways, and EA to quantify solar energy loss mechanisms. A special "Millennium Session" celebrated the most significant achievements in the field over the last three decades.

\section{Polymer, Semiconductor, and Oxide Electronics}

Polyaniline, known as a conductive polymer, has been transformed to a "metal," according to B. Wessling (Ormecon Chemie, Germany) who gave a presentation in Symposium $S$ on electroactive polymers. The new metallic form of polyaniline is created during the first dispersion of raw polyaniline powder. This is the crucial step for the practical use of this material, which is otherwise insoluble and unmoldable. approaches.
Dispersion allows for processing and use despite this material's intrinsic insolubility. The company has developed a number of applications in various technological fields for this new conductive polymer. In corrosion protection, this "organic metal" exhibits noble metal property, and can act as a catalyst. Both properties together allow for a surface passivation reaction whereby a passivating iron oxide $\left(\mathrm{Fe}_{2} \mathrm{O}_{3}\right)$ layer is formed, providing corrosion protection about five times that of conventional methods. In printed circuit board fabrication, again noble metal and catalytic properties allow for the deposition of a new solderability preservation finish. For the manufacturing of OLEDs and PLEDs, it can serve as a hole in the injection layer. Wessling said that an appropriate dispersion state providing 30,10, or even $5 \mathrm{~nm}$ small colloidal particles in controlled and reproducible form is crucial for reliable LED efficiency and lifetime.

Symposium S covered the use of organic or polymeric materials as the active layer in TFTs, sensors, and electrochromic and photovoltaic devices as well as in LEDs. The use of sensitive, selective materials for detection of TNT in land mines was described by T.M. Swager (MIT). A. Dodabalapur (Lucent/Bell Labs) described how electroactive organics in TFTs can act as chemical sensors with ppm detection capabilities. The fabrication of invertors and ring-ocillators made with organic materials was discussed by G.H. Gelinck (Philips Research Labs, The Netherlands). Also in the area of organic LEDs, M.E. Thompson (Univ. of Southern California) and S.R. Forrest (Princeton Univ.) separately described high external quantum efficiencies obtainable in OLEDs by incorporating phosphorescent dyes.

Symposium T was the latest in a series of symposia on the topic of wide bandgap electronic devices, covering GaN, SiC, and associated materials. Among the various sessions, those covering nitridebased devices included GaN-based MOSFETs, which are expected to provide low leakage and reduced power consumption as compared to FETs utilizing Schottky barrier gates.

The Materials Science of Novel OxideBased Electronics, Symposium U, focused on active electronics based entirely on metal oxide materials. One of the major advances in the field is the development of viable $p$-type TCOs. One of the class of materials being investigated are copperbased oxides. H. Ohta (Japan Science and Technology Corp.) described a working transparent UV-emitting LED made using $\mathrm{SrCu}_{2} \mathrm{O}_{2}$ in conjunction with $n$-type $\mathrm{ZnO}$. 


\section{Biomaterials}

Symposium DD provided the opportunity for interaction between various subcommunities in the biomedical field. R.L. Chisholm (Northwestern Univ. Medical School) gave a presentation on live cell fluorescence imaging methods that are elucidating migration of cells. M.P. Vacanti (Univ. of Massachusetts Medical School) reported on the generation of spinal cord tissue in adult rats and partial recovery of motor function from neural progenitor cells seeded on a polymer composite scaffold.

Symposium FF addressed fundamental scientific aspects and advances in applications of polymers at surfaces/interfaces/thin films, and effects on processing and adhesion. Various sessions focused on structure and dynamics in thin films, structure and properties of polymer/polymer and polymer wall interfaces, effects of polymer interfaces on processing, friction and lubrication, behavior of polyelectrolytes and proteins at surfaces, and mechanical aspects of soft biomaterial interfaces.

\section{Other Technical Topics}

New magnetic transistor devices are beginning to compete with semiconductor RAM chips, offering high-density nonvolatile storage and eliminating the limitations of computer boot-up time. In Symposium F, W.J. Gallagher (IBM) presented a 1 Kbit demonstration RAM chip. B.D. Terris (IBM) and C.A. Ross (MIT) described patterned magnetic media devices for ultrahigh-density, terabyte magnetic recording. Terris gave a talk on work being conducted at IBM on patterned magnetic media for high-density data storage. The current goal for storage density is $100 \mathrm{Gbits} / \mathrm{in}^{2}$, to delay superparamagnetism, with the nearterm goal being $1 \mathrm{Tbit} / \mathrm{in}^{2}$. He described the use of ion-beam patterning, using both uniform and focused ion beams to create single domain magnetic bits in a patterned magnetic film. MFM imaging as a function of the magnetic field was used to study the sub-100-nm islands. Ross discussed patterned media in which each bit is stored in a lithographically defined magnetic element with two stable magnetization states.

Presentations in Symposium G showed that current requirements to increase magnetic information storage density necessitates atomic-level control and characterization of media and head material microstructure and composition. Highlights included talks on magnetic nonvolatile memory elements such as by S.P.P. Parkin (IBM) on tunneling and G.A. Prinz (NREL) on vertical magnetoresistive memory elements.
In Symposium Y, S.C. Ventura (SRI Int'l) described a new multilayer solid freeform fabrication process, direct photoshaping, under development in which visible digital light projection is used as a maskless tool to build images on photocurable ceramic dispersions (ceramic powders in photopolymerizable liquid monomers) by floodlight exposure. For each layer the projected image is changed according to the CAD data describing the object being built. Solidification takes place by photocuring of the exposed areas. Multiple layers are dispensed and photocured to fabricate the desired object. A final rinse with a suitable solvent removes any uncured ceramic dispersion. The porous freeformed "green" part can then be fired and sintered into a dense ceramic part. This ceramic-forming process is based on visible-light photo gelcasting. The photocurable ceramic dispersion is prepared from a mixture of ceramic powder and organic monomers containing a visible light photoinitiator. Upon photoexposure, the monomers solidify into a polymer thus forming a gelcast green body. Digital Light Processing ${ }^{\mathrm{TM}}$ technology (developed by TI) enables SRI International to project digital, high-resolution, high-brightness, high-contrast visible light to photocure and form components with a good degree of accuracy. The process of direct photoshaping is being applied to the fabrication of ceramic gas turbine components for commercial and military applications.

Core areas in the field of the granular state of matter was covered in Symposium BB. Sessions focused on granular structure, nonlinear waves in granular media, granular flows, vibrated and rotated granular media, and stress distributions. In "Jamming: Glasses, Foams, and Granular Matter" S.R. Nagel (Univ. of Chicago) addressed how jamming (lowering stress) in a granular material is related to the glass transition temperature. Nagel presented a "jamming phase diagram" relating glass formation in supercooled liquids to jamming in granular materials and foams.

The central theme of Symposium $\mathrm{H}$ on Metal and Alloy Corrosion was fundamental atomistic processes occurring at the electrochemical interface. Topics included corrosion of aluminum alloys and novel measurement techniques. By using a newly developed video-speed STM, O.M. Magnusson (Univ. of Ulm, Germany) described real-time movement of individual atoms during copper localization.

Symposium I highlighted efforts by researchers to achieve a detailed scientific understanding of atomic scale mechanisms of growth, and the use of models for this purpose. Vapor deposition under- pins coating and thin film technologies used in fields ranging from microelectronics to aircraft engines. S.M. Rossnagel (IBM) introduced an ALD approach for depositing tantalum diffusion barriers on the interiors of trenches and vias cut into the surface of silica-coated wafers.

Symposium K presented an overview of the state-of-the-art in the self-assembly of morphological and compositionally defined structures, such as quantum dots and quantum wires during semiconductor heteroepitaxy. One of the highlights was an extensive discussion of spatial variation in composition within selfassembled structures.

Preceding Symposium L was a tutorial on in situ electron-beam techniques (J. Eckstein, Univ. of Illinois), time-of-flight scattering and recoil spectroscopy (O. Auciello, ANL), and spectroscopic ellipsometry (E.A. Irene, Univ. of North Carolina). Within the Symposium, A.K. Schmid (SNL) showed a LEEM video in his talk on the propulsion of mobile metal clusters by surface tension effects. A panel discussion highlighted the importance of in situ observations in the development of quantitative models of materials behavior and growth dynamics.

Symposium M, Morphology and Dynamics of Crystal Surfaces in Complex Molecular Systems, focused on physical and structural studies of growth and dissolution on inorganic, organic, and macromolecular crystal surfaces. Fields as diverse as geochemistry, corrosion science, structural biology, food science, pharmaceutical production, and crystal growth were represented. Several talks focused on the interaction of crystal surfaces with adsorbates, organic films, or other heterointerfaces in solutions, with special attention to the role of stereochemistry in controlling crystallographic orientation and crystal morphology.

In Symposium $\mathrm{N}$ on Materials for Separations in Analytical Chemistry, S. Hjerten (Uppsala Univ., Sweden) presented work on imprinted polymers that selectively removed single proteins from protein mixtures, which is a step toward "artificial antibodies." V.T. Remcho (Oregon State Univ.) addressed the use of MIPs for molecular recognition. Synthesis in the presence of a template molecule results in the formation of specific recognition sites within a polymer. The potential of MIP-based chromatographic sorbents for combinatorial library screening (simulated using a group of structurally similar pharmaceuticals and similar compounds) was demonstrated. The library compounds sharing key structural features of the template were better recognized by the MIP, exhibiting a high degree of selective interaction. 
Combinatorial Chemistry and Materials Science refers to high-throughput synthesis/evaluation techniques that have the potential for significantly increased understanding of the relationship between composition/processing and materials properties, and was the focus of Symposium W. The theme of exploiting parallel synthesis techniques to explore composition space as well as processing space was introduced. As an example, S. Semanchik (NIST) described "microplate arrays" wherein individual temperature-controlled membranes are fabricated in a MEMS-like fashion and are then used as the substrate for subsequent film deposition. The membranes can be addressed using CMOS circuitry built onto the chip.

In Symposium Q on Flat-Panel Display Materials, highlights included a discussion of hole transport polymers for automotive display applications, analysis of the latest theories of carbon electron emission, and a full session on semiconductor TFT arrays. In Symposium R on Electron Emissive Materials and Vacuum Microelectronics, highlights included a description of very small field emitter structures fabricated using ion-track lithography to develop the masks used for lithographic processes, development of Mo and Co silicide field emission arrays that exhibit relative inertness to environment, and work function reduction.

\section{Overviews for the Nonspecialists}

Along with the joint talks with the Education Workshop (Symposium HH), Symposium $\mathrm{X}$ on Frontiers of Materials Research included talks that addressed the practical topics of biotechnology and chemical warfare; materials to fight counterfeiting; the role of materials in the sinking of the RMS Titanic; B. Illman's (USDA Forest Service) talk on "Recycle and Remediate Nature's Strongest Polymers from Wood"; and R.A. Tromp's (IBM T.J. Watson Research Center) presentation on "Have You Ever Seen a Crystal Grow?"

Tromp described in situ processes studied using LEEM. The LEEM has an energy range of $0-100 \mathrm{eV}$, a field of view of $1-20 \mu \mathrm{m}$, and the capability for in situ crystal growth and etching. Accompanying his talk with several videos of in situ observations in the LEEM, Tromp described several studies. Some of the studies include Ag growth on $\mathrm{Si}(111)$, buried interfaces in $\mathrm{CaF}_{2} / \mathrm{Si}(111)$, the use of spin-polarized LEEM for surface magnetic imaging such as for Co in $\mathrm{Au}(111)$, Si homoepitaxial growth to study the role of kinetics versus thermodynamics, and the observation of $\mathrm{Si}$ nucleation at higher temperatures. $\mathrm{He}$ also described SiGe growth to form quan- tum dots on $\mathrm{Si}(001)$ and changes in surface morphology.

Illman overviewed the structural properties of wood, and the fungal mechanisms that alter and degrade structural integrity. She described synchrotronbased methods to study elemental distribution and speciation as probes of decay chemistry. She also described bioremediation of metal-treated wood.

Chemical warfare includes the use of traditional reactive agents such as mustard gas, as well as the use of the newer nerve agents such as organophosphorous compounds. In his presentation on biotechnology to combat chemical warfare and to manage chemical warfare agents, A. Russell (Univ. of Pittsburgh) concentrated on these nerve gases. Issues associated with managing chemical warfare agents include decontamination, disposal, and demilitarization. Biocatalysis, that uses enzymes for catalytic hydrolysis, is emerging as a viable technique for detection and detoxification. Enzymatic bioremediation has several advantages: It is environmentally benign, has minimal side reactions due to specificity, and can be used with existing "decon" strategies. The end product is unique to each agent and allows for specific identification.

C.W. Lantman (Flex Products Inc.) described the use of interference optics for fighting counterfeiting. He said that interference optics using constructive interference creates color at an angle to defeat "digifeits," which are counterfeits using modern copying technologies. He further described various types of product counterfeiting, including software, identity (passports and credit cards), and pharmaceuticals. Some emerging technologies to tackle counterfeiting include linear photopolymerization, biomimetic microstructures, nanostructural gratings, and laserimaged interference coatings. In the example of $\mathrm{OVP}^{\mathrm{TM}}$, which is a thin-film optical device used as a pigment, layers are deposited sequentially and controlled to molecular tolerances, and constructive interference creates color at an angle.

The discovery in 1985 of the RMS Titanic wreck and the subsequent recovery of some of the material enabled a study of the steel and wrought iron used in the ship's construction. T.P. Weihs (Johns Hopkins Univ.) accompanied an expedition to the Titanic wreck site in the North Atlantic and performed several tests there. He then conducted more detailed tests on land. Weihs explored the brittle steel theory supposedly caused by the cold water temperatures of the ocean and he examined the idea of weak rivets. He concluded that steel used was state- of-the-art for 1911, and fracture toughness of the hull steel at ice brine temperatures was adequate for the application. However, there was considerable variability in the wrought iron feedstock, which caused variability in rivet properties due to inconsistent fabrication procedures and due to the pressure to speed up production. In one study, 19 out of 48 rivets either had too much slag, too coarse of slag, or both. Weaker seams would have let go during impact. A comparison was made with Titanic's sister ship, the RMS Olympic, which during its lifetime underwent a number of collisions, yet did not suffer Titanic's fate, and was scrapped in 1936 with the title "Old Reliable."

For further details about the technical content of the Meeting, read the following symposium summaries and see the published proceedings.

\section{From Photovoltaics to Photodiodes, Amorphous Silicon Moves into the Next Millennium}

(See MRS Proceedings Volume 609)

Symposium A on Amorphous and Heterogeneous Silicon Thin Films-2000 provided a forum for scientists and engineers to exchange results of their latest research on topics ranging from silicon thin film physics and chemistry to novel device design and engineering. Some of the presentations covered fundamental studies including the growth of amorphous and heterogeneous silicon films, their ordering transitions, and creation and annealing of deleterious metastable defects. Other sessions covered a variety of applications ranging from traditional large area photovoltaic and display devices to novel microscale photodiodes for retinal stimulation and nanoscale crystallite devices for memories.

A "Millennium Session" celebrated the most important achievements of the last three decades in the field of amorphous and microcrystalline silicon thin films. $H$. Fritzsche (ECD) began this session with an entertaining account of the events of the early 1970s that led to the discovery of hydrogen incorporation in amorphous silicon as the key to its excellent semiconducting properties. Y. Hamakawa (Ritsumeikan Univ., Japan) followed with an account of the device developments in Japan that stimulated the intense scientific and engineering efforts in amorphous and microcrystalline semiconductors which continue to this day. I. Solomon (Ecole Polytechnique, France) concluded the session with a broad perspective of the progress of the silicon thin film field and optimistic predictions of continued progress in both science and applications. 
Another special session focused on the physics of amorphous and microcrystalline silicon solar cells with invited papers by R. Carius (Juelich, Germany), K. Lips (Hahn-Meitner Inst., Germany), and E.A. Schiff (Syracuse Univ.). In these presentations, advanced characterization techniques were highlighted whereby the electronic processes in solar cell materials could be probed in the actual device configuration. Techniques described in these papers included photothermal deflection spectroscopy to quantify solar energyloss mechanisms, EDMR to identify the transport and recombination pathways, and EA to gain insight into the origins of open-circuit voltage limitations.

The third event featured a session on heterogeneous silicon materials and their growth and transport properties, with an invited paper by I. Shimizu (Tokyo Inst. Tech., Japan). The session started with a brief introduction by C.R. Wronski (Penn State Univ.) who announced Shimizu's imminent retirement and highlighted his many contributions to materials science and technology, including growth chemistry, novel materials, and device development. Shimizu then described silicon film growth from fluorinated gas sources that provide control over the texture of polycrystalline silicon thin films to obtain remarkably high electronic carrier mobility.

Symposium Support: AKZO Nobel, BP Solarex, dPix, Energy Conversion Devices, Fuji Electric RED, NREL, Penn State, United Solar Systems, and Xerox PARC.

\section{Achieving J unction Abruptness \\ Added to Si Front-End Processing Constraints \\ (See MRS Proceedings Volume 610)}

Symposium B, Si Front-End ProcessingPhysics and Technology of Dopant-Defect Interactions II, continued last year's theme in deepening the fundamental understanding of the mechanisms of dopant-defect interaction. At the same time, through a number of excellent industrial talks, future issues in device scaling were quantitatively linked with the requirements placed on dopant profile and junction formation, emphasizing not only shallow junction depth and high-concentration activation, but also the extremely tight limits on junction abruptness.

Multiple implant and annealing schemes were presented to improve the relationship between junction depth and sheet resistance, as required for future device technologies. The anneal processes spanned from extremely low temperature preanneals to extremely high temperature pulsed laser processing. Experimental data and modeling of dopants after spike anneals were presented. A number of papers evaluating implantation of alternative chemical species for defect engineering, including $\mathrm{C}, \mathrm{N}, \mathrm{F}, \mathrm{O}, \mathrm{Cl}, \mathrm{S}$, Se and $\mathrm{Br}$, showed interesting results. For defects, high energy $\mathrm{MeV}$ implants into thin SOI layer were used to effectively implant vacancies and dramatically altered dopant diffusion.

In probing the dopant-defect interaction, new experimental data for the early phases of cluster formation were presented together with modeling which further their understanding. At the same time, critical analysis of the predictive power of $a b$ initio calculations was given, pointing out how the underlying assumptions can dramatically change the resulting calculations of defect energetics. A talk was given which showed how genetic algorithms can be applied to materials science as a new method to extract fundamental parameters.

A session on dopant characterization discussed the state-of-the-art for some prominent 2D profiling techniques, including SCM, SSRM, and electron holography. As several talks on device scaling pointed out, the requirements on junctions for sub$100-\mathrm{nm}$ devices are 2D in nature, so that $2 \mathrm{D}$ profile measurements are necessary for on-going development.

To mark this year 2000 symposium,
R.B. Fair (Duke Univ.) gave an excellent historical overview of the field of implant and annealing in silicon devices.

Symposium Support: Applied Materials, Eaton Corp., Intel Corp., Lucent Technologies/Bell Labs, Sula Technologies, and Varian Semiconductor Equipment Assn.

\section{Device and Gate Processing Gains from High-k and Silic ide Materials (See MRS Proceedings Volume 611)}

A new symposium on Gate Stack and Silicide Issues in Silicon Processing (Symp. C) debuted this year. Researchers described new materials and processes that are needed for deeply scaled CMOS. The Symposium was kicked off by a tutorial on Silicide Trends and Stress Effects in Silicide Formation.

A session on high- $k$ materials for gate insulators opened the Symposium. G. Wilk (Lucent Technologies) gave an invited talk on sputtered $\mathrm{Zr}$ and Hf silicate films. These amorphous materials were found to form directly on silicon and were stable to high temperature. J.H. Stathis (IBM) began the afternoon session by discussing the limits of $\mathrm{SiO}_{2}$ extendibility, which researchers now believe to be slightly less than $2 \mathrm{~nm}$, although a later talk by D.A. Muller (Lucent Technologies) suggested that this might be too pessimistic. Contributed talks on Tuesday looked at $\mathrm{ZrO}_{2}$ and its silicates, BST, $\mathrm{Ta}_{2} \mathrm{O}_{5}, \mathrm{La}_{2} \mathrm{O}_{3}$, $\mathrm{TiO}_{2}, \mathrm{CeO}_{2}$, and epitaxial perovskites.

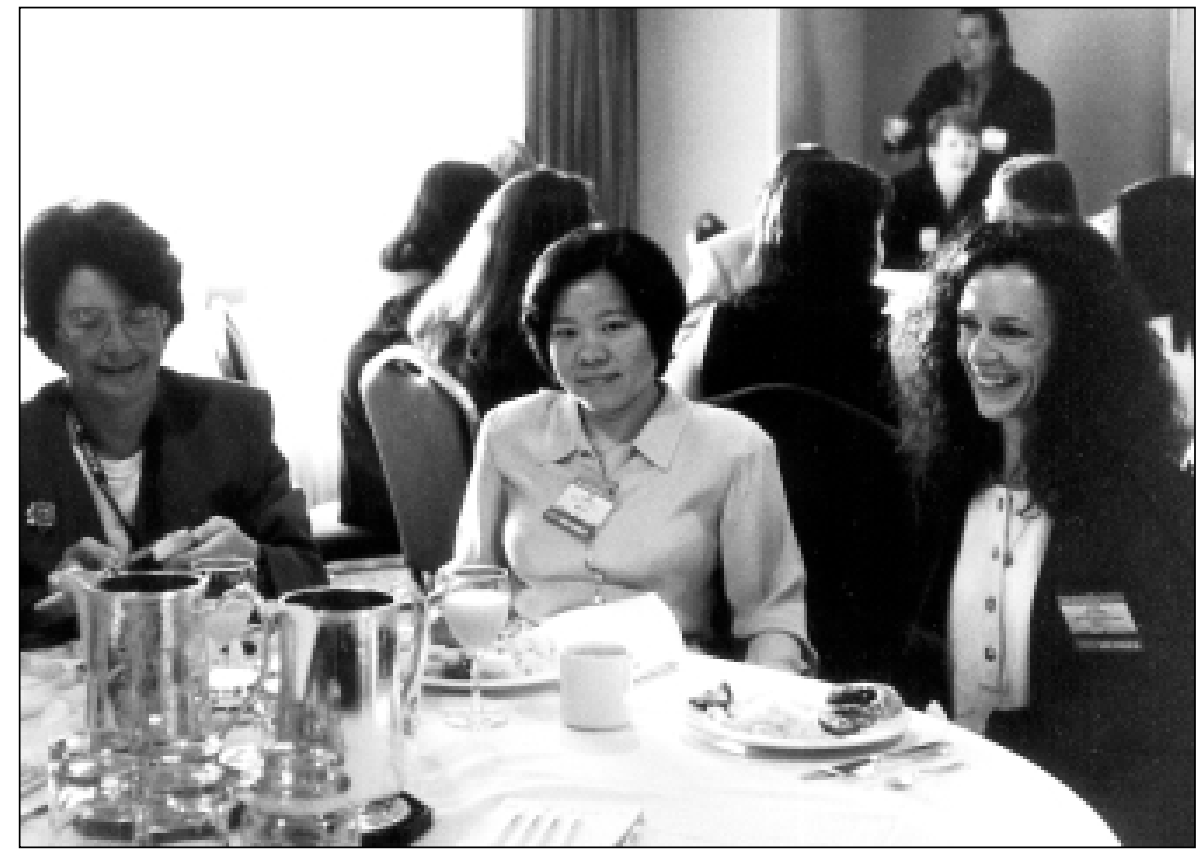

About 50 MRS members participated in a breakfast discussion on April 26 to explore what role MRS members might play in helping to advance the professional standing of women in the sciences. 
The third session on high- $k$ gate insulators also included a discussion of gate electrodes and the gate formation process for high- $k$ materials. K. Suguro (Toshiba Corp., Japan) described damascene $\mathrm{Al} / \mathrm{TiN}$ and $\mathrm{W} / \mathrm{TiN}$ processes on $\mathrm{Ta}_{2} \mathrm{O}_{5}$ and $\mathrm{TiO}_{2}$. Other speakers discussed WN, TiN, and W. P. Ranade (UC-Berkeley) described a process by which the Mo work function could be adjusted by hundreds of $\mathrm{meV}$ to provide a psuedo dual gate approach. An invited talk by F.H. Baumann

\section{Poster Prizes Awarded at the $\mathbf{2 0 0 0}$ MRS Spring Meeting}

The 2000 MRS Spring Meeting chairs divided themselves between the San Francisco Marriott and the Argent hotels during the poster sessions in order to choose the best poster presentation from each hotel. Poster prizes of $\$ 500$ along with a certificate were presented for the following posters: Thin Film Transistors made of $950^{\circ} \mathrm{C}$ Polysilicon on Steel Foil, M. Wu and S. Wagner (Princeton Univ.) (A28.5); Controlling $\mathrm{CoSi}_{2}$ Nucleation: The Effect of Entropy of Mixing, C. Detavernier, R.L. Van Meirhaeghe, and F. Cardon (Univ. of Gent) and K. Maex (IMEC, Belgium); (C7.9); Evolution of Surface Morphology and Epilayer Tilt in Highly Mismatched InSb Films, X. Weng and R.S. Goldman (Univ. of Michigan) and D.L. Partin and J.P. Heremans (Delphi Research and Development Center) (K5.15); Enhancement of Efficiency in Organic Photo-Voltaic Devices by Optical Design, L.S. Roman, L.A.A. Pettersson, T. Granlund, T. Nyberg, and O. Inganas (Linkoping Univ.) (S6.51); Formation and Characterization of Oxides on GaN Surfaces, D. Mistele, T. Rotter, F. Fedler, H. Klausing, O.K. Semchinova, J. Stemmer, J. Aderhold, and J. Graul (Univ. of Hanover) (T6.20); Preparation and Characterization of $\mathrm{LiCoO}_{2}$ Thin Films on Porous Ni/NiO Cathodes for MCFC by Complex Sol-Gel Process (CSGP), W. Lada, A. Deptula, B. Sartowska, T. Olczak, and A.G. Chmielewski (Inst. of Nuclear Chemistry and Technology, Warsaw) and M. Carewska, S. Scaccia, E. Simonetti, L. Giorgi, and A. Moreno (ENEA-CRECasaccia, Italy) (U5.5); SelfAssembling Molecules in Tissue Engineering, D.A. Harrington, P.L. Drzal, J.J. Hwang, and S.I. Stupp (Northwestern Univ.) (DD5.2); and Chemical and Structural Characterization of Silane Adhesion-Promoting Film for Use in Microelectronic Packaging, M.L.Jenkins, D. Pantelidis, and J.C. Bravman (Stanford Univ.) (FF5.12).

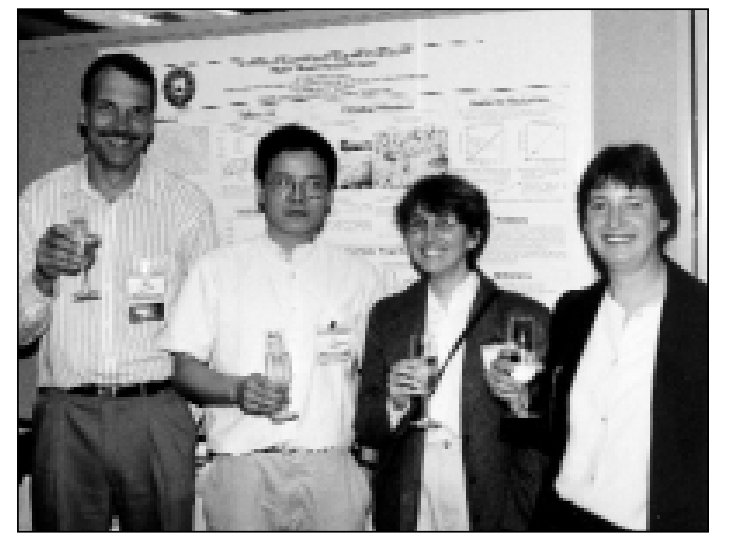

Meeting Chairs Kevin S. J ones (left) and Frances M. Ross (right) with poster award recipients Xiaojun Weng (inside left) and Rachel S. Goldman (inside right).

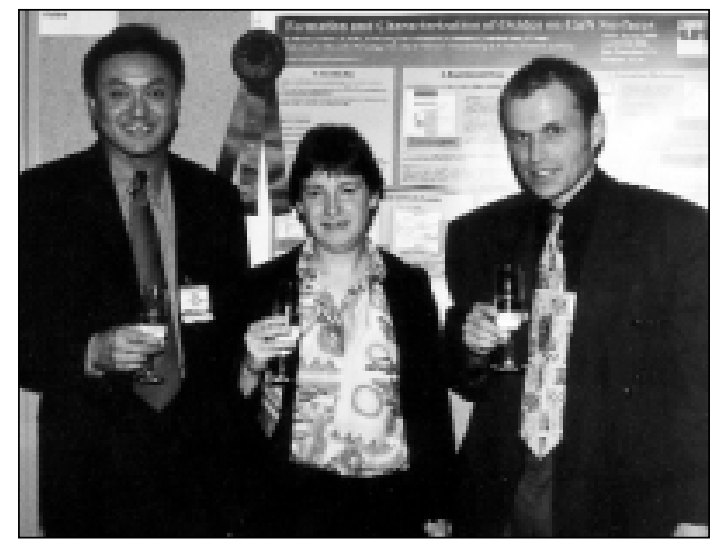

Meeting Chairs Robert Q. Hwang (left) and Frances M. Ross (center) with poster award recipient David Mistele (right).
(Lucent Technologies) explored the limits of $\mathrm{SiO}_{2}$ scaling and contributed talks were given on nitrided $\mathrm{SiO}_{2}$ and UHV silicon nitride.

The silicide aspect of the Symposium was kicked off with an exciting invited talk by F.M. Ross (IBM) who received the Outstanding Young Investigator award for her work. Ross showed real-time video images of the microstructure of various reactions. Prominent among them were the formation of silicides and the effects of grain boundaries on these reactions. The technical sessions on silicides were anchored by five invited talks. K. Wieczorek (AMD, Germany) highlighted the integration issues with $\mathrm{CoSi}_{2}$, K. Maex (IMEC, Belgium) discussed silicides for $0.13 \mu \mathrm{m}$ and beyond, C. Lavoie (IBM) demonstrated the effect of incorporated transition elements on $\mathrm{TiSi}_{2}$ formation, K.-I. Goto (Fujitsu Labs., Japan) studied $\mathrm{CoSi}_{2}$ leakage mechanisms, and R.T. Tung (Lucent Technologies) discussed epitaxial silicide contacts and junctions. Contributed papers covered a range of silicides $\left(\mathrm{TiSi}_{2}\right.$, $\mathrm{CoSi}_{2}, \mathrm{NiSi}$, and epitaxial) and a range of topics including stress, shallow junctions, integration issues, nucleation and growth mechanisms, and selective growth. The poster session was highlighted by C. Detravernier's (Univ. of Gent, Belgium) poster on the effect of entropy of mixing on controlling $\mathrm{CoSi}_{2}$ nucleation, which received a Best Poster Award.

Symposium Support: Advanced Micro Devices, Applied Materials, and IBM Microelectronics.

\section{Mechanical Properties and Characterization of Low-k Materials Important for Sticking with Copper Metallization}

(See MRS Proceedings Volume 612)

Symposium D, Materials, Technology and Reliability for Advanced Interconnects and Low- $k$ Dielectrics, started with an interdisciplinary Tutorial, $\mathrm{Cu}$ Interconnects: What Are the Issues? The Symposium presented papers on the critical issues related to performance, electrodeposition, and corrosion of $\mathrm{Cu}$.

The Symposium started with a session on the mechanical properties of low- $k$ dielectrics. Adhesion of thin metal and dielectric films and reliability of $\mathrm{Cu}$ created a lot of discussion. Both fundamental and applied research were covered, illuminating how the research for better adhesion measurements and the research to improve adhesion go hand-in-hand. The role of the microstructure in blanket $\mathrm{Cu}$ layers and in narrow features and its relation to electromigration and to the chemical-mechanical polishing of $\mathrm{Cu}$ was addressed by several contributions. 
Presentations on the relation between materials properties and electrical performance provided valuable information in the debate on which will be the low-k dielectric of choice. A critical area discussed was the characterization of porous materials and the comparison of the various techniques to do such characterization. Various techniques based on high resolution x-ray reflectivity, small-angle neutron scattering, positron annihilation and on ellipsometric porosimetry were outlined, identifying the specifics of each technique toward the interpretation of pore size distribution and interconnectivity, for example.

Symposium Support: ASM, ATMI, Dow Chemical, Novellus Systems, and SEMATECH.

\section{From Fundamentals to Applications of Chemical-Mechanical Polishing Studied (See MRS Proceedings Volume 613)}

Symposium E, Chemical-Mechanical Polishing-Fundamentals and Materials Issues, showcased some of the latest research being undertaken in this area, both at the universities and at the industry level. The topics ranged from fundamentals to the application of CMP in siliconbased semiconductor processing. The various topics covered by University researchers included the following: process mechanisms (including slurry chemistry and abrasive effects in metal and oxide CMP), slurry stability, chemical interactions between pads and slurries, slurry film thickness, interfacial pressure and friction measurements, modeling of fluid flow, pad properties and pattern dependencies, and removal of particles and metallic waste from used slurries. A few presentations were also given on the polishing of newer semiconductor materials like silicon carbide. The topics covered by industry presenters included modeling of the CMP process as a chemical reactor, studies on aluminum and copper damascene processes, along with some presentations on poly-silicon and STI CMP. Additionally, there was a presentation on a novel spin-etch planarization process, along with some studies on using ozonated water for post-CMP cleaning.

\section{Progress Rapid in Magnetic Materials for Information Storage}

(See MRS Proceedings Volume 614)

Exponential growth in information technologies has resulted in an explosion in the need for data storage with increased speed and capacity. In response, development of magnetic materials and structures is accelerating dramatically. Little time remains to study performance of new materials before fabrication into devices.
To that end, Symposium F on Magnetic Materials, Structures, and Processing for Information Storage addressed both research on magnetic materials and technology to fabricate new devices.

Five years ago, giant magnetoresistance, colossal magnetoresistance, and spin-dependent tunneling were names applied to novel magnetic materials with poorly understood properties. Currently, GMR, CMR and SDT materials are incorporated into increasingly complicated devices, some of which are now products. Fabrication, characterization, modeling, and use of these structures for sensors and recording heads is now well established. New magnetic transistor devices may compete with semiconductor RAM chips to offer fast, high-density, nonvolatile storage that eliminates the need for computer boot-up time. W.J. Gallagher, (IBM) demonstrated a 1 kbit magnetic RAM chip and G.A. Prinz, (NRL) presented design improvements.

Longitudinal magnetic recording is a more mature field, which involves designing around physical limits to scaling the technology. Accordingly, papers focused on nanoscale characterization of microstructure by TEM (W.J. MoberlyChan, Komag), by XRD (B.K. Tanner, Univ. of Durham, UK), of chemical composition by TEM (J.E. Wittig, Vanderbilt Univ.) and of magnetodynamics by SH-MOKE (T.J. Silva, NIST). Another series of papers discussed ways to avoid the scaling limitations of traditional media by patterning magnetic media devices for ultrahighdensity, terabyte magnetic recording (B.D. Terris, IBM and C.A. Ross, MIT).

Symposium Support: Epion, IBM, Kurt J. Lesker Co., Plasma-Therm, Seagate Technology, and Veeco Instruments.

\section{Metallic Thin Films Find Role in Magnetic Storage and Nonvolatile Memory \\ (See MRS Proceedings Volume 615)}

Polycrystalline Metal and Magnetic Thin Films, Symposium G, provided a penetrating look into several of the hot issues in metal and magnetic thin films. The drive to increase magnetic information storage density demands atomic-level control and characterization of media and head material microstructure and composition. Several speakers, including M. Mirzamaani (IBM) and B.K. Tanner (Univ. of Durham, UK) showed the importance of a strong link between growth and characterization efforts. The lively competition between the structural characterization capabilities of TEM and $x$-ray diffraction has clearly been fed by advances in both, resulting in the ability to characterize composition, tex- ture, and grain structure in media and layered magnetoresistive structures.

The excitement in magnetic nonvolatile memory elements was highlighted by several talks describing tunneling (e.g., S.P.P. Parkin of IBM on vertical magnetoresistive and G.A. Prinz of NRL on memory elements). A theoretical approach to the differences between tunneling in epitaxial and amorphous barriers were described in a talk by P.M. Levy (New York Univ.), where the role of the interface density of electronic states was highlighted. The important practical issue of exchange biasing was discussed by E.D. Dahlberg (Univ. of Minnesota).

Discussions of the evolution of thin-film interfaces and grain structures again highlighted the critical roll of characterization, including in situ techniques such as measurements of conductivity (W.F. Egelhoff, NIST) and stress (P. Gergaud, CNRS, France) to investigate intermixing and growth modes. Development of grain texture characterized by focused ion beam imaging (M.E. Gross, Lucent Technologies) and the stress distributions in $\mathrm{Si}$ systems characterized by micro-raman (I. DeWolf, IMEC) have also led to increased ability to understand and control thin film properties.

Symposium Support: Advanced Micro Devices, IBM, and Seagate Technology.

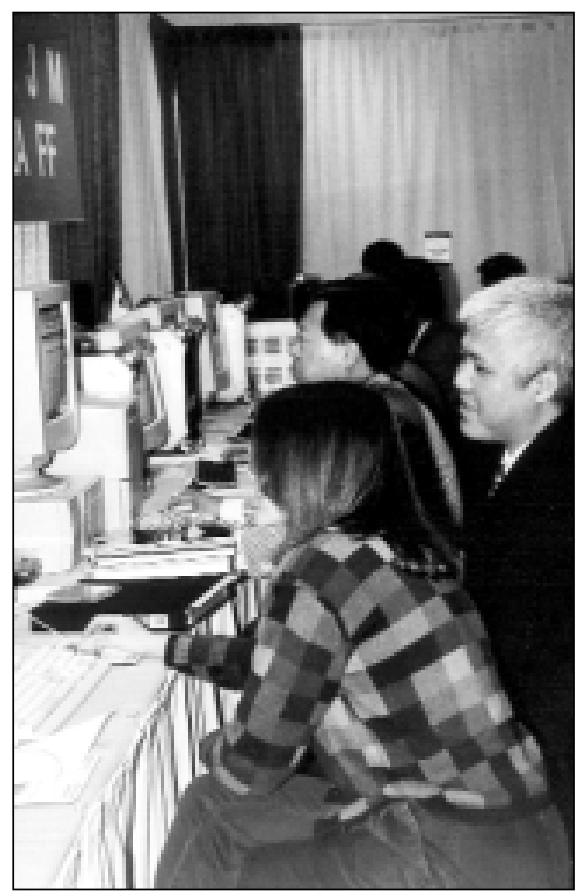

The manuscript room was busy as participants submitted their papers for the electronic proceedings. 


\section{Examination of Atomistic Processes Helps Clarify Electrochemical Interface During Corrosion}

Although the topics covered in Symposium $\mathrm{H}$ on Corrosion of Metals and Alloys ranged from the corrosion of aluminum alloys to novel measurement techniques and oxide film growth and morphology, within this diverse set ran a central theme focusing on the fundamental atomistic processes occurring at the electrochemical interface. O.M. Magnusson (Univ. of Ulm, Germany) showed, using their newly developed video-speed STM, the real time movement of individual atoms during copper dissolution. Efforts continue in the quest to understand the factors controlling localized dissolution as groups at SNL described how they have elegantly employed nanofabrication techniques to engineer model surface defects in materials. These activities include anion vacancies in surface films and the generation of intermetallic particles. Complimentary to these experimental studies, the progress being made in the use of computer models to simulate both film-growth and dissolution at the solid liquid interface was described by J.D. Erlebacher (Harvard Univ.) and J.R. Rustad (PNNL).

Symposium Support: AFOSR, Philips Analytical, and Scribner Associates.

\section{Vapor Deposition Techniques Meet Evolving Needs from Microelectronics to Engines \\ (See MRS Proceedings Volume 616)}

Vapor deposition is widely used to synthesize the thin films and coatings that underpin numerous technologies from microelectronics to aircraft engines. As the structural and compositional complexity of these vapor-deposited materials has increased, many methods of vapor deposition have been developed. The design of the deposition approaches and their control systems is increasingly dependent upon a detailed scientific understanding of the atomic scale mechanisms of growth and is beginning to rely upon the use of models that link these mechanism insights to growth conditions. Symposium I on New Methods, Mechanisms and Models of Vapor Deposition explored these interlinked issues and their applications in micro- and magnetoelectronics, hard coatings, photovoltaics, high- $\mathrm{T}_{c}$ thin films, and III-N materials. The symposium was typified by the invited presentation of S.M. Rossnagel (IBM) who introduced a new atomic layer deposition approach for depositing tantalum diffusion barriers on the interior of trenches and vias cut into the surface of silica-coated wafers. In this approach, a monolayer of a Ta-containing precursor compound is uniformly adsorbed onto the wafer surface and chemically decomposed on the surface, and then the process is repeated to build up the high integrity barriers needed for deep submicron copper interconnects of the future. S.P.P. Parkin (IBM) likewise described how submonolayer control of the coating architecture during the growth of multilayers is enabling the synthesis of new magnetoelectronic devices. Invited and contributed presentations described many other novel deposition techniques, reviewed the rapid advances in in situ sensor technology, assessed the impact of new control approaches and investigated the use of mathematical models to simulate reactor conditions and the growth of atomic scale structures during the deposition process.

\section{Lasers Interact with Solids for Micromachining, Deposition, and Processing}

(See MRS Proceedings Volume 617)

Symposium J on Laser-Solid Interactions for Materials Processing covered a diverse range of topics and materials associated with laser interactions with solid materials. These included fundamental studies of desorption, nanoparticle formation, laser writing and micromachining, and pulsed-laser deposition. Highlights included recent results from ORNL on understanding the formation of carbon nanotubes by laser ablation. The formation of 3D arrays in glass using nonlinear interactions at short pulse widths was described by E. Mazur (Harvard Univ.). Several interesting developments in pulsed-laser deposition were also reported. Included was the use of UV radiation to assist the oxidation kinetics in oxide film growth, as reported by R.K. Singh (Univ. of Florida). D.H.A. Blank (Univ. of Twente, The Netherlands) described efforts to understand the layerby-layer growth mechanisms in pulsedlaser deposited oxide thin films. In addition, A. Pique (NRL) described a matrixassisted laser ablation technique for the deposition of organic thin films.

Symposium Support: Epion Corp., Lambda Physik, Neocera and ORNL.

\section{Self-Assembly Dots the Landscape of Semiconductor Heteroepitaxy}

\section{(See MRS Proceedings Volume 618)}

Symposium K on Morphological and Compositional Evolution of Heteroepitaxial Semiconductor Thin Films provided an overview of the state-of-the-art in understanding the self-assembly of morphologically and compositionally defined structures during semiconductor heteroepitaxy. Structures such as quantum dots and quantum wires were studied using a wide variety of materials systems and growth techniques.

A number of methods to control the size and ordering of the self-assembled structures were discussed. These included the growth of multilayer arrays, the nucleation of structures at step edges on vicinal surfaces, the doping of the substrate surface with foreign atoms, the use of patterned and/or compliant substrates, and a cooperative nucleation mechanism in which islands and pits are alternately formed.

Another highlight was an extensive discussion of spatial variations in composition within self-assembled structures. In addition to alloying and surface segregation, strain fields induced by structural shapes, dislocations, and interactions between structures were shown to have significant effects. Numerical solutions of continuum elastic equations were used to model stress - and hence, compositionaldistributions.

Free energy analysis, continuum growth models, rate equations, phase field models, kinetic Monte-Carlo, and both firstprinciples and empirical atomistics were among the many other modeling approaches featured by the Symposium. Both kinetic and thermodynamic theories of dot formation were presented, and a consensus about the conditions for which each mechanism should dominate still seemed to be lacking. Another, perhaps related, controversy involved the initial stages of dot growth. Both a sudden transition to islands larger than some critical size and a continuous evolution in island height were reported. Various shapes for small islands were also reported. Several speakers suggested that some of these differences might result from variations in temperature.

Symposium Support: EPI MBE Products Group, $k$-Space Associates, NSF, and SVT Associates.

\section{Theory and In Situ Characterization Critical for Oxide and Metal Epitaxy}

(See MRS Proceedings Volume 619)

In Symposium L on Recent Developments in Oxide and Metal Epitaxy-Theory and Environment, particular emphasis was placed on in situ characterization techniques, enhancing efficiency in developing an understanding of these materials. Tutorials covering in situ electron-beam techniques (J. Eckstein, Univ. of Illinois at Urbana-Champaign), time-of-flight scattering and recoil spectroscopy (O. Auciello, ANL), and spectroscopic ellipsometry (E.A. Irene, Univ. of North Carolina) started the program Sunday afternoon. 
Dislocation dynamics in metal thin films were presented from in situ LEEM (Univ. of Illinois, Urbana-Champaign) and TEM experiments (LBNL). A. Schmid (SNL) showed a LEEM video of the propulsion of mobile metal clusters propelled by surface- tension effects, followed by a demonstration of similar effects with floating camphor particles. Several talks on complex oxide epitaxy highlighted the role of in situ techniques for tailoring highly complex microstructures using MBE and PLD.
Developments in the growth of these oxides on silicon substrates were presented. A panel discussion highlighted the importance of in situ observations in the development of quantitative models of materials behavior and growth dynamics. The tech-
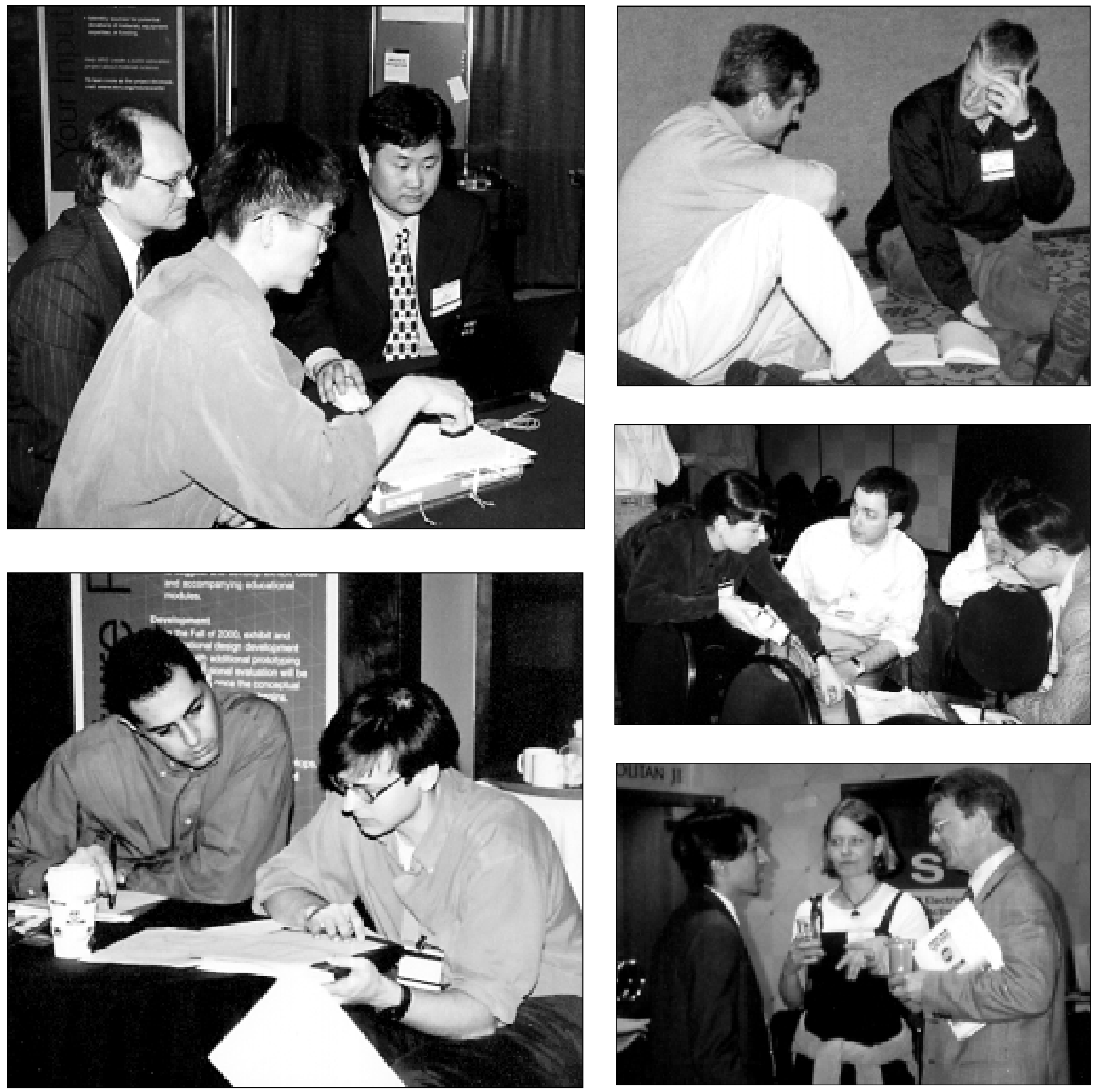

Researchers find many opportunities to discuss their work between talks at the MRS Spring Meeting. 


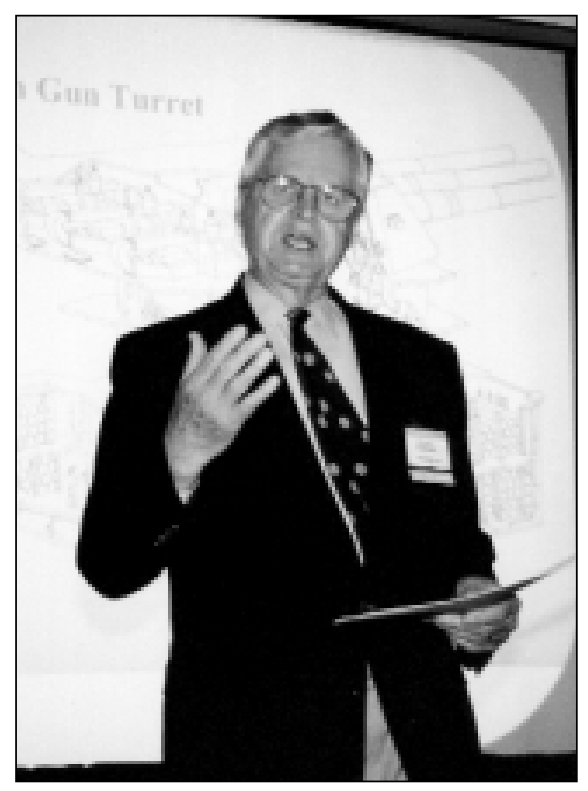

In Symposium GG on Analyzing,

Predicting, and Preventing Disasters,

Richard L. Schwoebel describes his investigation of the explosion aboard the USS lowa battleship.

nological importance of metals and oxides was highlighted in the case of magnetic devices, with the presentation of novel selfassembly phenomena in magnetic multilayers and a clear articulation of some of the critical issues that need to be addressed.

Symposium Support: ANL,DOE/Ames Lab, IBM, and IMRE.

\section{Surface Science, Steriochemistry, and Steps Tell Story of Morphology in Molecular Systems}

(See MRS Proceedings Volume 620)

The focus of Symposium M on Morphology and Dynamics of Crystal Surfaces in Complex Molecular Systems was physical and structural studies of growth and dissolution on inorganic, organic, and macromolecular crystal surfaces. Results were presented on molecular assembly and surface dynamics in complex molecular systems from fields as diverse as geochemistry, crystal growth, structural biology, corrosion science, pharmaceutical production, and food science. A number of major themes emerged from these presentations. First among these was the expanding application of surface science tools and analytical approaches to investigations of crystallization in all of these fields. Several talks highlighted in situ methods of investigating crystal/fluid interfaces. AFM had clearly achieved primacy in this field, although the continued importance of phase shifting interferometry was apparent as was the growing significance of synchrotron-based x-ray methods. Many speakers focused on the interaction of crystal surfaces with adsorbates, organic films, or other heterointerfaces in solutions, paying particular attention to the role of steriochemistry in controlling both crystallographic orientation and crystal morphology. This aspect of crystallization was discussed in relation to mineralogical, biological, and synthetic systems. Several researchers reported results on systems in which the step edges were very smooth, demonstrating the general importance of 1D nucleation along steps as a determining factor in growth kinetics. Investigation of this issue, along with that of step fluctuations, liquid structure, and adsorbate-step interactions appear likely to dominate fundamental research into the growth of molecular crystals over the next few years.

\section{Symposium Support: LLNL and NASA.}

\section{Separation Processes Bring Together Views on Chemical Analysis}

A one-day Symposium on Materials for Separations in Analytical Chemistry (Symposium N) was held to bring together analytical chemists and materials scientists to address new materials challenges in chemical analysis. On this subject held for the first time at an MRS meeting, research on molecular imprinting of materials was presented by S. Hjerten (Uppsala Univ., Sweden) who discussed work on imprinted polymers that selectively removed single proteins from protein mixtures as a step toward "artificial antibodies." In related research, V. Remcho (Oregon State Univ.) showed results using molecular imprinting to mimic cellular receptors for drug discovery. K.J. Shea (UC-Irvine) presented separation materials based on hybrid inorganic/organic sol-gel materials. R.P. Fisk (Waters Corp.) also presented work on hybrid materials and surface modifications that yield materials having enhanced stability at high $\mathrm{pH}$. C.C. Landry (Univ. of Vermont) presented the synthesis and application of mesoporous silica for chromatography. Several nonsilica phases for separations were discussed. B. Trammel (Univ. of Minnesota) presented work on zirconia phases and their modifications to enable separations at extremes of temperature and pH. C.P. Palmer (New Mexico Tech.) and M.R. Schure (Rohm and Haas Co.) presented work on polyelectrolytes as replacable separation media for capillary electrokinetic chromatography. D.W. Neyer (SNL) presented a novel method of high pressure generation using electrokinetic pumping and its application to the separation of proteins in a compact chromatographic system having no moving parts. S.M. Steinike (Shimadzu Scientific Instruments) presented a system that generated ultralow flow rates for gradient elution in liquid chromatography. In the area of gel electrophoresis, B.A. Buchholz (Northwestern Univ.) and J.-L. Viovy (Curie Inst., France) discussed advances in the development of gels that have temperature-dependent viscosity to aid in the loading of capillaries for DNA sequencing. C. Yu and M. Laemmerhofer (both of UC-Berkeley) presented new work on the use of monolithic polymer phases for chip-based and capillary-based electrochromatography. M.A. Hayes (Arizona State Univ.) presented work on the control of electroosmotic flow using radial fields and J.J. Pesek (San Jose State Univ.) discussed surface treatments for open tubular capillary electrochromatography. M.G. Alonso-Amigo (Jenoptik Mikrotechnik) presented hot embossing methods for the fabrication of microanalytical devices.

Symposium Support: ARO and SNL.

\section{Relevance of Materials Computation to Technology Contemplated}

Symposium O on Materials Computation-Progress Towards Technological Impact explored the degree to which materials computation is already impacting technology and ways in which its relevance might be increased. The Symposium spanned a wide range of technical specialties, including chemical processes, interfacial properties, optical and magnetic properties, alloy design, and mechanical performance. J.K. Norskov (Technical Univ. of Denmark) presented a compelling example of the use of first-principles calculations in close collaboration with experiment to aid in the design of new catalysts. However, these success stories were clearly still the exception and not the general mode for the vast majority of materials computational efforts.

The Symposium featured a panel discussion on accelerating the impact of materials computation. After the completion of seven short perspective presentations by representatives from universities, government laboratories, commercial software houses, and industry, the panel and audience engaged in a lively dialogue. J. Williams (Ohio State Univ.) issued the challenge that improved modeling capabilities are crucial to the future of materials science in order to bring materials development times more in line with shrinking product development times. W. Wendl (Motorola) suggested that multidisciplinary teams and close interaction with customers are essential for tack- 
ling industrial problems, and B. Harmon (Ames) emphasized that such a structure requires a cultural change away from the dominant single-investigator approach. D.M. Teter (SNL) stressed the need for computational modeling experts to interact with materials producers and end users in order to better understand their needs and constraints. Issues related to education and training and the development and distribution of software dominated much of the discussion.

Symposium Support: Ford Motor Co., NIST, and SNL.

\section{Multiscale Modeling Applied to Polymers}

Symposium P on Multiscale Modeling of Organic Materials, and particularly on polymeric materials, highlighted major advances in this rapidly growing field. Although recent advances in computational physics, materials science, and chemistry make it possible in some cases to predict the properties and understand phenomena in organic materials, significant challenges are still encountered in bridging the range of size and time scales between atomistic simulations and continuum models for the macroscopic material systems essential to industrial design and processing. These challenges were addressed at the atomistic level by methods combining quantum mechanical and molecular mechanics approaches that enable, for example, the modeling of silicon surfaces and silicon-based materials, or atomistic simulations that include continuum solvation techniques, making it possible to study complex polymeric systems such as dendritic polymers as well as extensive force-field developments for quantitatively predicting structural and dynamical properties of materials. Methodologies for mesoscale simulations were also highlighted in the symposium, for example, in using dynamic density functional theory to study the self-assembly of block polyelectrolyte molecules into robust polymer vesicles, in deriving patterns for liquid crystal polymers discerned at the mesoscale level of modeling, and in the use of lattice chain models to study polymeric materials. Furthermore, a recent national project initiated in Japan was described in which a seamless zooming system of code developments, particularly for mesoscale modeling, was developed. It would allow virtual experiments for polymeric materials at various spatial and time scales, and would be applicable for example to the study of phase-separated structures of thin polymer blend films. The importance of using the appropriate multiscale model for spe- cific material problems was emphasized; this was demonstrated in applications to dense polymer systems with wide-ranging time scales, and also for glass-forming polymers.

\section{Nanotubes, Phosphors, Polymers Find their Place in Flat-Panel Displays} (See MRS Proceedings Volume 621)

Symposium Q on Flat-Panel Display Materials opened with two sessions held jointly with Symposium R on ElectronEmissive Materials and Vacuum Microelectronics. A major topic for these sessions consisted of electron-emission and field-emission displays from carbon nanotubes. J. Robertson (Cambridge Univ., UK) discussed the latest theories of carbon electron emission, and J.M. Kim (Samsung, Korea) showed a nanotube FED. D.R. Tallant (SNL) reviewed fundamental mechanisms limiting the efficiency of cathodo- and photoluminesent phosphors. One session was organized jointly with Symposium S on Electrically Active Polymers. J.C. Sturm (Princeton Univ.) reviewed ink jet printing for polymer LEDs, and H. Fujikawa (Toyota, Japan) discussed the hole transport polymers they are studying for automotive displays. In another half day session, S. Tanaka (Tottori Univ., Japan) and P. Green (Planar Systems) gave reviews of phosphors used in electroluminescent displays. A full day of presentations was devoted to semiconductors for TFT arrays. G.N. Parsons (North Carolina State Univ.), S.-K. Joo (Seoul National Univ., Korea), S.D. Brotherton (Philips, UK), and P.M. Smith (LLNL) discussed various aspects of thin film deposition, recrystallization, and processing for TFTs.

\section{Field-Emitter Arrays and Carbon- Based Materials Share Their Colors (See MRS Proceedings Volume 621)}

Symposium R on Electron-Emissive Materials and Vacuum Microelectronics contained a well-rounded overview of electron source issues, theory, applications, and technology. Carbon nanotubes, carbonbased materials, and field emitter arrays were extensively discussed, from fundamental theory to fabrication and state-ofthe-art development. The nature of the field emission processes, particularly in the carbon-based materials, discussed by J. Robertson (Cambridge Univ., UK), and R.G. Forbes (Univ. of Surrey, UK) motivated extensive discussions. Fabrication methods for carbon nanotubes (e.g., laser ablation and CVD) were described and compared by O. Zhou (Univ. of North Carolina) and others. J.M. Kim (Samsung, Japan) described carbon nanotube utiliza- tion in a large area, full-color field-emission display. R.G. Musket (LLNL) showed exceptionally small field emitter structures fabricated by using ion track lithography to develop the masks used for lithographic processes. J. D. Lee (Seoul Nattional Univ., Korea) discussed the development of Mo and Co Silicide FEAs which exhibited relative inertness to environment and work function reduction, and D. Palmer (MCNC) described current stabilization of silicon field emitters. The benefits of engineered coatings (e.g., carbides and others) for work function reduction and resistance to sputtering damage, as well as protection schemes to prevent emitter failure due to arc damage (e.g., resistive stabilization and current limiting schemes) meshed extraordinarily well with applications well-suited for cold cathodes: D.R. Whaley (Northrop) successfully used molybdenum field emitter arrays as a thermionic replacement in a microwave power tube, thereby bringing a long-term goal of vacuum microelectronics substantially closer to commercial realization; and while displays and rf amplifiers have been long-term goals for cold cathode development, space-based applications (e.g., low-power electric propulsion thrusters and electrodynamic tethers for propellantless propulsion) would benefit from low voltage operation and sputtering resistance offered by the panoply of electron source materials.

Symposium Support: Altair Technologies and ONR.

\section{Inceasing Electron Mobility in Electroactive Polymers Poses Challenges}

Symposium $S$ on Electroactive Polymers brought together a diverse group of chemists, physicists, and engineers working on electroactive organics. The eight sessions, including a joint session with Symposium Q on Flat Panel Display Materials, highlighted the fundamental and practical issues faced by scientists trying to utilize organic or polymeric materials as the active layer in light-emitting diodes (OLEDs and PLEDs), TFTs, sensors, and electrochromic and photovoltaic devices. While the commercial potential for these materials is large, several scientific challenges remain.

In the session on sensor applications T.M. Swager (MIT) discussed some sensitive and selective materials for the detection of TNT in land mines. New research presented at this Symposium demonstrated how the environmental sensitivity of some electroactive organics could be an advantage. A. Dodabalapur (Lucent Technologies) showed that TFTs made with an active organic layer can serve as chemical sensors with ppm detection capabilities. 


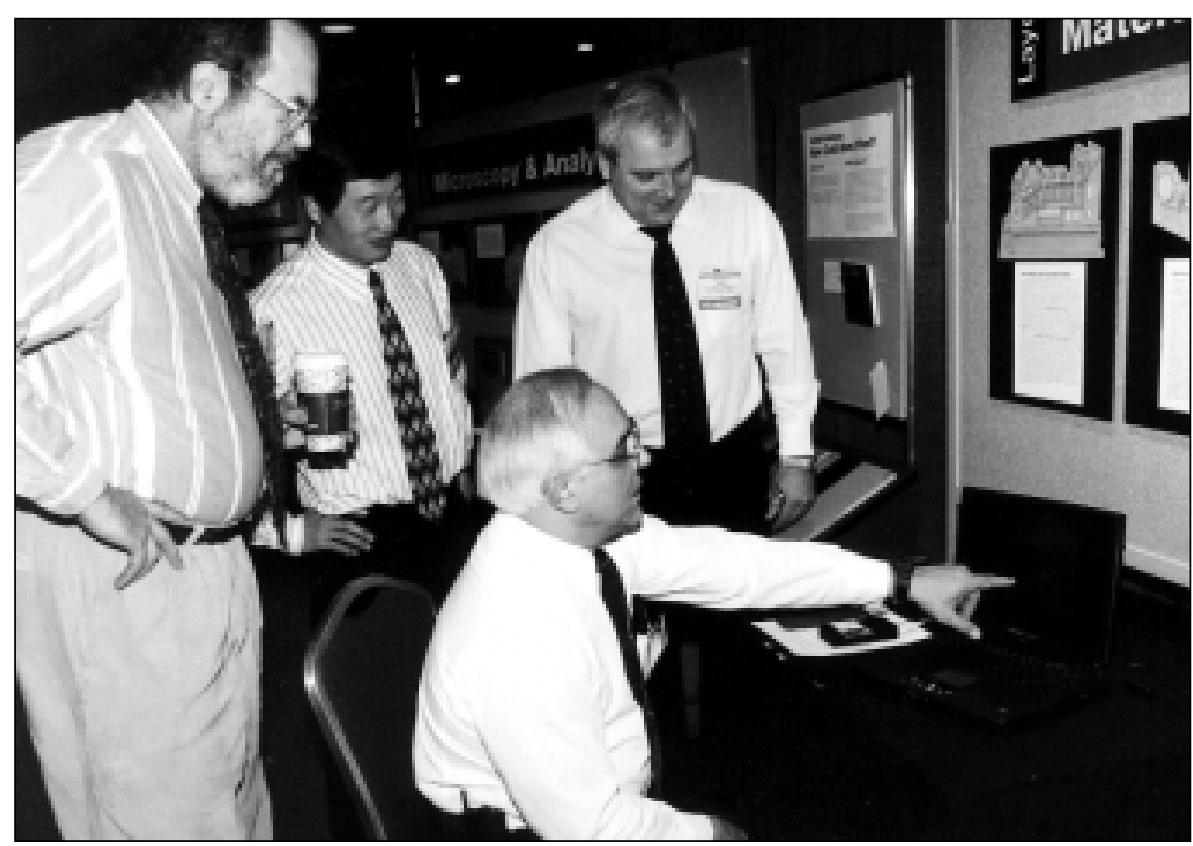

Orlando Auciello (ANL) demonstrates "smart card" technology based on nonvolatile ferroelectric random access memory technology with $\mathrm{Pt} / \mathrm{SrBi}_{2} \mathrm{Ta}_{2} \mathrm{O}_{9} / \mathrm{Pt}$ capacitors, which recently were introduced into the market. These smart cards are used for multiple applications such as fare payment for public transportation; payment for gasoline; and access to public, private, and government institutions and to sport, musical, and other events.

A significant challenge facing this field is to increase the electron mobility. In a session devoted to TFTs, H.E. Katz (Lucent Technologies) introduced an $n$-channel material with the highest electron mobility seen in organics to date. G.H. Gelinck (Philips Research Labs., The Netherlands) discussed the fabrication of invertors and ring-oscillators made with organic materials. Several sessions of the Symposium were devoted to organic and polymeric LEDs. M.E. Thompson (Univ. of Southern California) and S. Forrest (Princeton Univ.), in separate talks, detailed how to obtain high external quantum efficiencies in OLEDs by incorporating phosphorescent dyes. B.J. Schwartz (UCLA) presented some new findings on the large impact of polymer morphology on photoluminescent efficiencies. J.C. Scott (IBM) described how cross-linking polyfluorenes via endfunctionalized groups minimizes excimer formation and increases device efficiency.

Symposium Support: Lucent Technologies/Bell Labs and Quantum.

\section{GaN, SiC Defects and Performance Examined}

(See MRS Proceedings Volume 622)

Symposium T on Wide-Bandgap Electronic Devices was the latest in a series of symposia held at MRS meetings on the growth, characterization, and processing of $\mathrm{GaN}, \mathrm{SiC}$, and associated materials. Several summaries of the current status of high power/high temperature-based GaN and $\mathrm{SiC}$ electronic devices were given. One topic of particular interest for $\mathrm{SiC}$ device applications was the effect of dislocations in $\mathrm{SiC}$ on reverse breakdown. Although defects in $\mathrm{SiC}$ related to micropipe formations have been reduced to approximately $1 \mathrm{~cm}^{-2}$, smaller scale defects in the range of $1 \times 10^{4} \mathrm{~cm}^{-2}$ have been observed, which have a huge impact on device performance. Presentations for nitride-based devices included GaN-based MOSFETs which are expected to provide low leakage and reduced power consumption as compared to FETs utilizing Schottky barrier gates, but a low density of states at the oxide/GaN interface is critical for high performance. MOSFETs utilizing either $\mathrm{Ga}_{2} \mathrm{O}_{3}\left(\mathrm{Gd}_{2} \mathrm{O}_{3}\right)$ or $\mathrm{SiO}_{2}$ oxide layers with low $\left(<10^{11} \mathrm{~cm}^{-2} \mathrm{eV}^{-1}\right)$ interface density of states were reported. The progress of AlGaN-based HEMTs for transmit and receive $(T / R)$ modules was discussed. The high performance that has been recently demonstrated by these devices, including high $x$-band power densities $(>9 \mathrm{~W} / \mathrm{mm})$ and very low microwave noise figures (NF $=0.8 \mathrm{~dB}$ at $10 \mathrm{GHz}$ ) with a large breakdown voltage $(>50 \mathrm{~V})$, suggests that
AlGaN HEMTs can be implemented into a full $\mathrm{T} / \mathrm{R}$ module with greater robustness than conventional technology. Device results were reported for GaN-based HBTs and BJTs in which active regions were grown by MBE. Several papers discussed the design optimization for GaN-based UV LEDs and photodetectors including the incorporation of In into the quantum wells. Processing papers covering the formation of ohmic contacts to $n-\mathrm{GaN}, p-\mathrm{GaN}$, and $n$-SiC, dry/wet etching, ion implantation, and high temperature anneals were also presented.

Symposium Support: ARO.

\section{Oxide-Based Electronics Development Yields n- and p-type Conductors}

(See MRS Proceedings Volume 623)

Symposium U on Materials Science of Novel Oxide-Based Electronics provided a preview of what is becoming a major research and development area: active electronics based entirely on metal oxide materials. The Symposium introduced a range of devices including FETs, steerable phased array microwave antennas, transparent diodes and a transparent UV-emitting LED.

J.A. Misewich and colleagues (IBM) presented three talks on buried oxide channel FETs based on the metal-insulator transition in Mott insulators such as underdoped YBCO. It is hoped that the highly nonlinear conductivity changes with gate-bias-induced charge injection will one day enable smaller transistors than currently achievable using Si-based technologies. Tunable dielectrics for microwave frequency applications, such as $\mathrm{Ba}_{1-x} \mathrm{Sr}_{x} \mathrm{TiO}_{3}$, were discussed by S.A. Alterovitz (NASA), C.M. Carlson (NREL), and P.K. Baumann (ANL). In these materials, the application of a dc electric field changes the microwave frequency dielectric constant which, in turn, allows for electronically tunable phase shifters and filters.

The development of viable $p$-type TCOs is one of the key new materials science developments which is enabling a new class of $p-n$ junction-based oxide devices. TCOs that are $n$-type, such as $\mathrm{ZnO}$ and $\mathrm{In}(\mathrm{Sn}) \mathrm{O}_{x}$, are well known, but the lack of a comparable $p$-type junction partner has limited their use to transparent conducting contacts, such as used in flat-panel displays or solar cells. However, in the past two years enormous progress has been made in materials for $p$-type TCOs. Presently, two distinct types of materials are being investigated. These include copper-based oxides with nominally $\mathrm{Cu}^{+1}$ ions in the stoichiometric host, such as $\mathrm{SrCu}_{2} \mathrm{O}_{2}$ and $\mathrm{CuAlO}_{2}$. These were discussed by H. Kawazoe (Hoya Corp.) and H. Yanagi (Tokyo Inst. of Technology, 
Japan) as well as L.F. Johnson (Navy Air Warfare Center) and the group of D.S. Ginley (NREL). Using $p$-type $\mathrm{SrCu}_{2} \mathrm{O}_{2}$ in conjunction with $n$-type $\mathrm{ZnO}, \mathrm{H}$. Ohta (Japan Science and Technology Corp., Japan) has made a working transparent UV-emitting LED. The second general class of $p$-type TCO materials are based on traditionally $n$-type TCOs such as $\mathrm{ZnO}$ doped to be $p$-type by co-doping. H. Katayama-Yoshida (Osaka Univ., Japan), who first proposed this idea, discussed the general applicability of co-doping to metal oxides as well as his explicit prediction that $\mathrm{ZnO}$ co-doped with $\mathrm{Ga}$ and $\mathrm{N}$ should be a $p$-type TCO. T. Kawai (Osaka Univ., Japan) presented convincing experimental work indicating such co-doping can, in fact, yield a $p$-type $\mathrm{ZnO}$ based TCO with doping levels up to $10^{20} / \mathrm{cm}^{3}$. With these rapid developments in the area of $p$ type transparent conducting oxides and the demonstration of a working UV-LED, the stage appears to be set for very rapid and exciting developments.

Symposium Support: IBM, NREL, and ONR.

\section{Direct Write Technology Requires Clean Starting Materials}

(See MRS Proceedings Volume 624)

The goal of Symposium V on Materials Development for Direct Write Technologies was to identify and develop new materials approaches based on the directwrite technique (transfer method) and the required electronic or other device performance (e.g., chemical sensors and biosensors, phosphor displays, and FETs). Many CAD/CAM approaches exist to direct write or transfer material patterns and each technique has its own merits and shortcomings. Among the approaches presented were plasma spray, laser particle guidance, MAPLE DW, laser CVD, micropen, ink jet, e-beam, focused ion beam, and several novel liquid or droplet microdispensing approaches. One common theme to all techniques is their dependence on high-quality starting materials, typically with specially tailored chemistries and/or rheological properties (viscosities, densities, and surface tension). Typical starting materials, sometimes termed "pastes" or "inks," can include combinations of powders, nanopowders, flakes, surface coatings and properties, organic precursors, binders, vehicles, solvents, dispersants, and surfactants. This wide variety of materials with applications as conductors, resistors, and dielectrics are being developed especially for low-temperature deposition $\left(<300-400^{\circ} \mathrm{C}\right)$. This will allow fabrication of passive electronic components and rf devices with the performance of conventional thick-film mate-

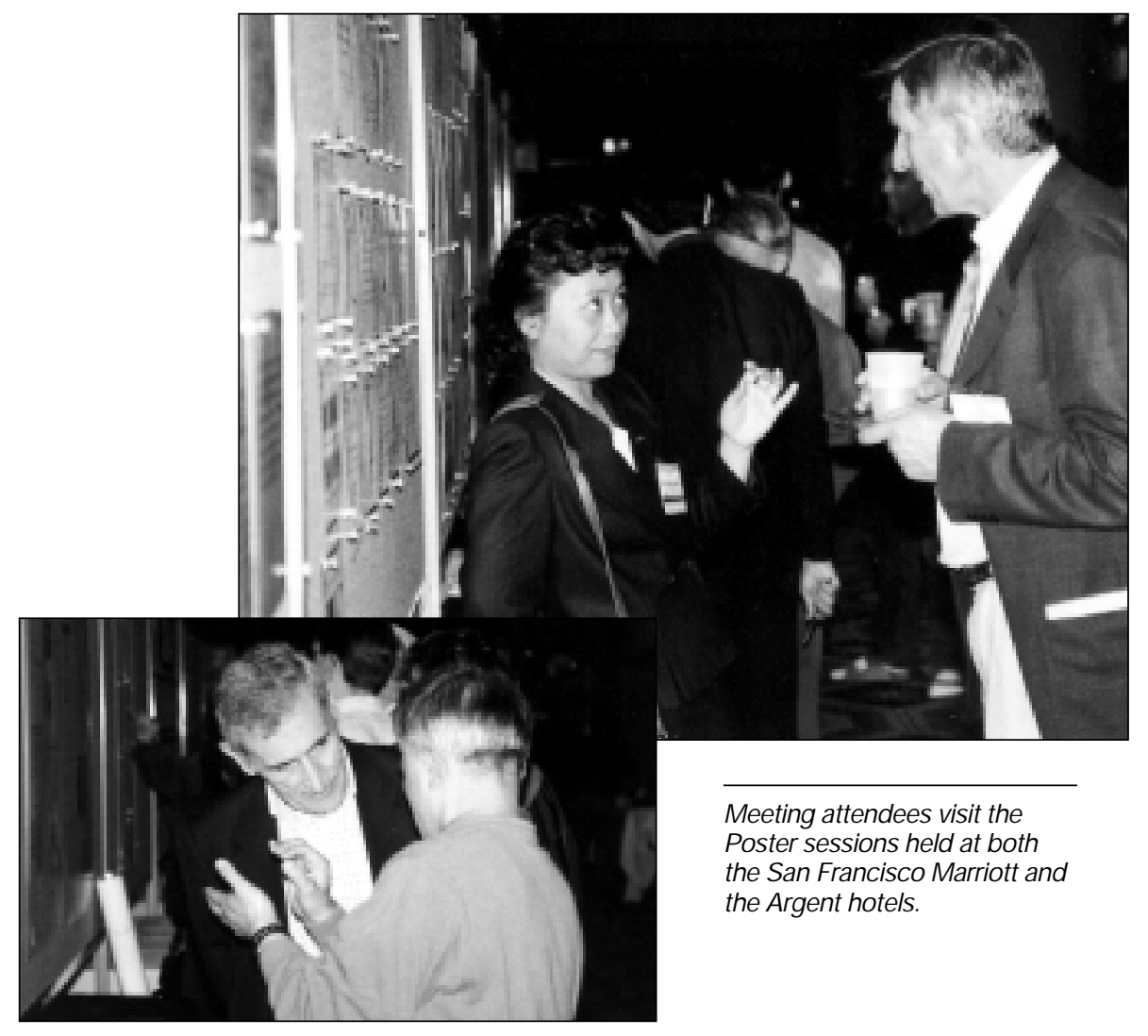

rials, but on low temperature flexible substrates (e.g., plastics, paper, and fabrics). Examples include silver, gold, palladium, and copper conductors, polymer thick film and ruthenium oxide-based resistors, and metal titanate-based dielectrics.

Fabricating high-quality crystalline materials at these temperatures is nearly impossible. One strategy is to form a highdensity packed powder combined with chemical precursors that form low melting point nanoparticles in situ to chemically weld the powder together. The chemistries used are wide ranging, but include various thermal, photochemical and vapor, liquid, and/or gas co-reactants. The chemistries require care to avoid carbon and hydroxide incorporation that will cause high losses at microwave frequencies or chemistries that are incompatible with other fabrication line processing steps. To further improve the electronic properties for low temperature processing, especially of the oxide ceramics, laser surface sintering is used to enhance particle-particle bonding. In most cases, individual direct-write techniques make trade-offs between particlebonding chemistries that are amenable with the transfer process and direct-write properties such as resolution or speed. The resolution of direct-write lines can be on the micron scale, speeds can be greater than $100 \mathrm{~mm} / \mathrm{s}$, and the electronic material properties are comparable to conventional screen-printed materials. Optimized materials for direct-write technologies result in deposition of finer features, minimal process variation, lower prototyping and production costs, higher manufacturing yields, decreased prototyping and production time, greater manufacturing flexibility, and reduced capital investments.

Symposium Support: CMS Technetronics, DARPA, Motorola Labs, Optomech Design Co., Potomac Photonics, and SFA.

\section{Combinatorial Chemistry Promises High Throughput}

High-throughput synthesis/evaluation techniques promise to impact many aspects of materials research, ranging from materials discovery to optimization, and from characterization to increased understanding of the relationship between composition/processing and the properties of materials. These techniques are generally grouped as "combinatorial chemistry," the title of Symposium W. In many cases the availability of data that is dense in composition/processing phase space leads not merely to a quantitatively increased number of samples per day that are investigated, but also a qualitative shift in the types of investigations that are feasible. 
For example, H.-W. Schmidt (Univ. Bayreuth, Germany) emphasized the increased reliability of data obtained by a parallel-synthesis approach, because the various individual cells are prepared under essentially identical conditions in a single run. A. Karim (NIST) described how the quantity of data obtained in a single experiment allowed a reliable phase diagram to be inferred.

The symposium introduced another theme, namely, exploiting parallel synthesis techniques to explore not only composition space but also processing space. A. Karim (NIST) described how this can be done using a continuous temperature gradient, and S. Semanchik (NIST) described the very powerful approach of "microplate arrays," in which individual temperature-controlled membranes are fabricated in a MEMS-like fashion, and then used as the substrate for subsequent film deposition. The membranes can be addressed using CMOS circuitry built onto the chip.

Many researchers described new directions for the application of high-throughput techniques, and described some of the lessons learned in each case. L.F. Schneemeyer (Lucent Technologies) introduced the topic of exploring highrefractive-index thin films for planar lightwave devices. X.-D. Xiang (LBNL) reported mapping the structure as a function of composition in the Ni-Fe alloy system, and showed that an anomaly in the Kerr rotation was associated with the bccfcc structure transition. He also described the advantages of a two-pronged approach in which continuous spreads are used to identify new candidate materials, and a discrete composition array is used to optimize or fine-tune properties, for example, by incorporating dopants. R. Schlecht (Lasergenics Corp.) described the need for an empirical, rapid throughput approach when confronted with the intractably complex interactions among the active centers in rare-earth-doped laser crystals and scintillator materials. D. Giaquinta (Symyx Technologies) said that a crucial requirement in materials discovery experiments is that sample preparation and evaluation must be meaningfully related to the ultimate form and function of the material-in particular, in bulk-like luminescent materials for displays. He introduced a model system for exploring these issues, namely, the lanthanideborate system. A. Karim (NIST) reported

\section{U.S. Government Grant Opportunities}

John Prater of the Army Research Office gave an overview of their funding opportunities for research in a variety of materials topics. The army has specific problems and concerns relating to their equipment and Prater said that materials research could help solve some of these while extending the capabilities of the army in many ways. Some of the specific areas the ARO is interested in include biomimetics, nanoscience, smart structures, compact power sources, and intelligent systems. Prater overviewed a number of materials research projects that $\mathrm{ARO}$ had recently funded. He encouraged researchers to apply for funding and also encouraged researchers to visit the ARO web site www.aro.army.mil.

Representatives also spoke from NSF and NIST's Advanced Technology Program.

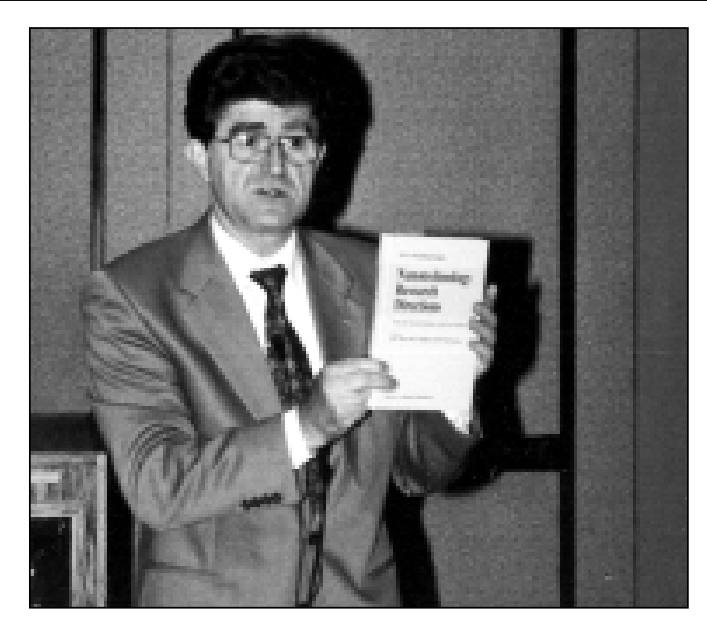

Michael Roco (NSF), chair of the NSTC Interagency Working Group on Nanoscience, Engineering, and Technology, shows U.S. government reports on nanotechnology that led to the National Nanotechnology Initiative. At the 2000 MRS Spring Meeting, he said that research could lead to new physical, chemical, and biological characteristics. He said that several opportunities are expected to open for research funding, but that more importantly, a number of new materials, new characteristics, and new areas of materials research are expected to open as a result of this initiative. on polymer dewetting as a function of film thickness and temperature. This work employed a controlled temperature gradient, and included data showing the phase boundary for various structural/wetting transitions. E.J. Amis (NIST) reported on use of combinatorial methods to discover useful biomaterials, specifically scaffold materials for cell growth, using cell growth itself as the assay.

Other researchers reported the specifics of methods that they developed to address particular problems, such as discovery of paint pigments (R. Jain, Symyx Technologies), discovery of new phosphors (T.X. Sun, GE), and hydrothermal synthesis of zeolites (T. Bein, Univ. of Munich, Germany). P.J. McGinn (Univ. of Notre Dame) described how a university researcher on a tight budget can nevertheless implement high-throughput techniques and obtain promising results.

Symposium Support: DuPont and Symyx Technologies.

\section{Building Polymers, Ceramics, and Metals the "Freeform" Way}

(See MRS Proceedings Volume 625)

Symposium Y on Solid Freeform and Additive Fabrication provided an up-todate review of the various materials and processing issues currently challenging the community interested in making polymer, ceramic, and metallic components by additive methods. Presentations covered methods ranging from LCVD to ink-jet printing processes.

A wide range of materials such as polymeric, metallic, and ceramic components for structural, biological, and electronic applications were covered. M.L. Griffith (SNL) provided an overview of the LENS process. She covered the recent developments in their ability to understand the relationship between processing parameters (laser power, scan velocity, and powder feed rate) and the final microstructure and properties, of materials such as tool steel and titanium made by the LENS process. B. Derby, (UMIST, UK) covered the physics of ink jet droplet formation using wax melts containing high concentrations (40 vol.\%) of ceramic particles, using drop-on-demand ink jet printing. He discussed their modeling and experimental results on the effects of process and materials parameters (such as driving voltage, frequency of the ink jet, and viscosity of the material) on drop formation. A joint session held with Symposium V on Materials Development for Direct Write Technologies covered the various materials approaches that are currently being developed for fabricating MICE. These talks described novel materials and depo- 
sition methods for low-temperature fabrication of passive electronic devices - such as conductors, insulators and capacitorson conformal surfaces.

Symposium Support: ONR and SNL.

\section{Opportunities in Thermoelectric Research Explored}

(See MRS Proceedings Volume 626)

Some of the highlights of Symposium Z on Thermoelectric Materials 2000-The Next-Generation Materials for Small-Scale Refrigeration and Power-Generation Applications were research results on quantum dot nanostructures of $\mathrm{PbTe}$ materials by T.C. Harmon (MIT Lincoln Labs). These materials appear to exhibit a substantial improvement over their bulk counterparts with a figure of merit $Z T=2$. The Kanatzidis group (Michigan State Univ.) presented an update on the material $\mathrm{CsBi}_{4} \mathrm{Te}_{6}$ since their announcement in Science 287 (2000) p. 1024. In addition, G.S. Nolas (Marlow Industries) presented data on partially $\mathrm{Yb}$-filled skutterudites with ZT $>1$ at $300^{\circ} \mathrm{C}$ which was independently verified by B.C. Sales (ORNL).

As in past Symposia, both bulk and thin-film thermoelectric materials research was well represented. In a special session, program managers W. Fuller-Mora (NSF), V. Browning (DARPA), J. Rowe (ARO), and J. Smith (DOE) discussed potential opportunities for thermoelectric research. This was followed by a short questionand-answer period.

Within the Symposium, three students received a certificate and a $\$ 150$ award for Best Student Presentation: Melissa A. Lane of the Department of Electrical and Computer Engineering, Northwestern University; Mark D. Ulrich of the Department of Physics at Auburn University; and Ganesh K. Ramachandran of the Department of Chemistry at Arizona State University.

Symposium Support: HI-Z Technology; Marlow Industries, and MMR Technologies.

\section{Millimeter Wave Technology Used for Characterization and Sensing}

Symposium AA on Millimeter/Submillimeter Wave Technology-Materials, Devices, and Diagnostics began with a session on characterization and diagnostics in which by C. Mann (Rutherford Appleton Lab, UK) presented an overview of millimeter and submillimeter wave components. Presenters P.P. Woskov (MIT) and S.K. Sundaram (PNNL) elaborated on the application of millimeter wave technology to diagnose high temperature processes under harsh environments using robust waveguides and novel designs. They described millimeter wave data for simulated high-level

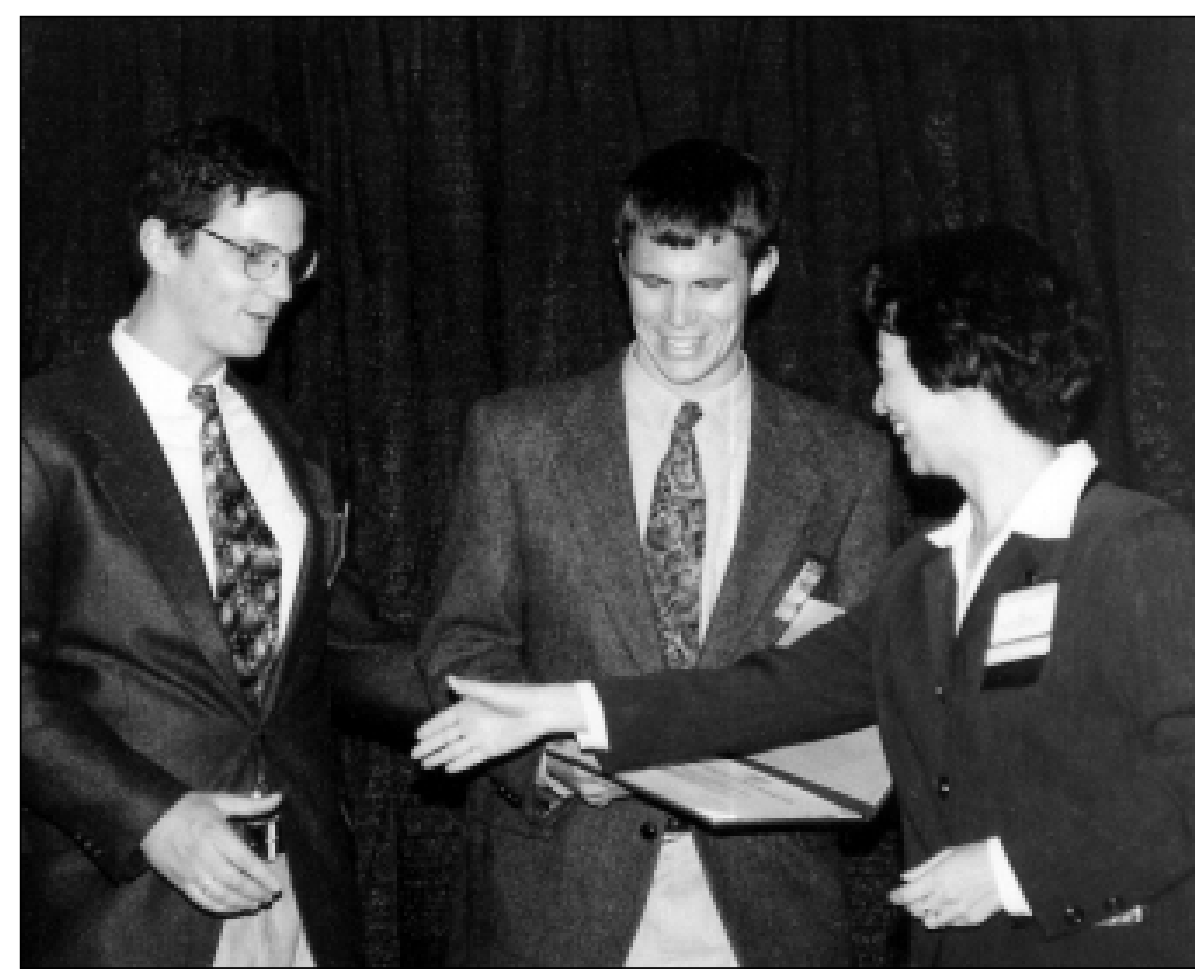

MRS Secretary Chuang Chuang Tsai (right) presents a University Chapter charter to Chapter Vice President Paul Rosenthal (left) and President Phil Mages from the University of CaliforniaSan Diego. New charters also went to California State Polytechnic University and Stanford University, and the new Louisiana MRS Section was recognized at the Meeting.

nuclear waste glasses that will be processed in a melter (vitrification) for safe disposal. C. Oleson (Oleson Microwave Labs) emphasized the importance of calibration for $110-325 \mathrm{GHz}$ vector network analysis. This discussion was followed by a description of vector measurements for dielectric characterization by P. Goy (AB Millimetre, France). V. Lyubchenko (Russian Acad. Sci., Russia) presented the potential of millimeter wave imaging for civilian applications. Two representatives from Japan, Y.-I. Ogita (Kanagawa Inst. Tech.) and T. Katoh (Mitsubishi Materials Corp.) summarized the application of $\mathrm{UV} /$ millimeter wave techniques to characterize subsurface damage of silicon and of hydrogen-implanted silicon.

The second session was devoted to material components and devices, starting with an overview of millimeter wave solid-state devices from N. Luhmann's research group from UC-Davis. J.G. Fleming (SNL) and T.W. Crowe (Univ. of Virginia) elaborated on fabrication and characterization of different diodes for application in the millimeter/submillimeter wave technology. S.W. McKnight (Northeastern Univ.) described the application of planar ferrite materials. V. Lyubchenko (Russia Acad. Sci., Russia) showed how millimeter waves could be used to measure water content and to monitor moisture in different materials. R. Freer (UMIST, UK) reviewed the microwave dielectric ceramics for communication application. D.K. Verma (Univ. of Central Florida) presented data on arsenic sulfide glasses used for this application as a waveguide.

Symposium Support: Oleson Microwave Lab.

\section{Going with the Flow of Granular Materials}

(See MRS Proceedings Volume 627)

Symposium BB on The Granular State represented core areas of this rapidly growing field that probes the granular state of matter. The sessions focused on granular structure, nonlinear waves in granular media, granular flows, vibrated and rotated granular media, and stress distributions.

In a joint session with Symposium GG on Analyzing, Predicting, and Preventing Disasters, one set of disasters was associated with granular materials involved in situations ranging from avalanches and earthquakes to grain elevator explosions.

Symposium Support: NSF, Schlumberger, and SNL. 


\section{Organic/Inorganic Hybrids Used for Nanostructured Materials \\ (See MRS Proceedings Volume 628)}

Symposium CC on Hybrid Organic/ Inorganic Materials addressed the synthesis, characterization, and properties of organic/inorganic hybrid materials. The tone was established by S.H. Phillips (AFRL) who described the use of partially oligomerized silsesquioxane polymers to develop a host of new materials with novel properties that include good hightemperature stability, abrasion resistance, and mechanical properties. The applicability of these materials to satisfy both Air Force needs and for commercial applications was emphasized. Presentations were given on complimentary and very simple, low-cost synthetic routes to related silsesquioxane materials; liquid crystalline behavior in silsesquioxane materials; tin oxide cluster complexes to prepare new organic/inorganic hybrids; and welldefined oxometallate clusters. Recent work was also presented on organophosphorous-based hybrids.

In the area of nanocomposite materials, Y. Chujo (Kyoto Univ.) described the use of highly polar polymers to make sol-gelprocessed, completely transparent silica/ polymer composites at all wt. compositions of each component. Presentations also described how changes in the structure of organic components used in the preparation of hybrid materials by sol-gel processing could be used to design welldefined porous materials, and on the development of controlled porosity catalysts. A presentation was given on methods of using nanocomposite hybrid materials for electronic materials to make extremely abrasion-resistant coatings on a broad spectrum of substrates.

In the area of nanoporous materials, researchers discussed the functionalization of nanopores to produce materials for photonic applications; the luminescence behavior of nanophosphors made by sol-gel methods; novel routes to mesoporous materials with very well-defined porosity and compositions, and also organically modified; and on mesoporous templating in silica films.

Of special interest was the work of J.E. Mark (Univ. of Cincinnati) and F. Babonneau (UPMC/CNRS, France) who described novel methods of analyzing hybrid materials using x-ray scattering and NMR techniques respectively.

There was also discussion on the use of hybrid materials for artificial organs and on the use of hybrid materials for combinatorial supports for DNA arrays. S.T. Hobson (U.S. Army Medical Research Inst.) gave an overview of the Army's efforts to devel-

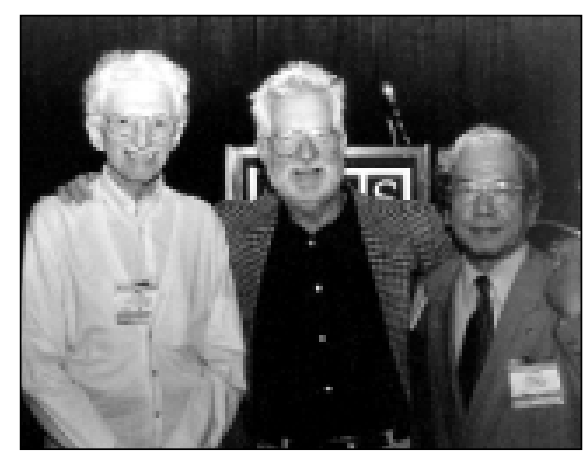

(Left to right) Ionel Solomon (Ecole Polytechnique, France), Hellmut Fritzsche (Energy Conversion Devices, Inc., USA), and Yoshihiro Hamakawa (Ritsumeikan Univ., J apan) addressed the history of amorphous materials in a special Millennium Session of Symposium A.

op antidote materials for chemical warfare agents based on hybrid materials.

\section{Diverse Communities Interface on Soft Biomaterials Challenges}

A hurdle to bringing the latest advances in materials science into the biomedical arena has been the lack of a suitable forum for cross-fertilization and collaboration between scientific subcommunities that typically do not interact substantially. Symposium DD on Interfacial Aspects of Soft Biomaterials brought together a fresh mix of scientists and clinicians from diverse backgrounds to discuss progress and remaining challenges in controlling the morphology and biochemistry of the interface between synthetic materials and biological fluids and tissues. One topical focus of the Symposium was recent advances in surface characterization in water-based environments. R.L. Chisholm (Northwestern Univ. Medical School) reported on live cell fluorescence imaging methods that are elucidating how cells migrate; L.S. Goldner (NIST) demonstrated optical imaging capability at nm length scales and the ability to resolve "blinking" of single fluorophores. Other contributions addressed novel methods of surface modification to control cell/surface interactions. J. Rühe (Univ. of Freiburg, Germany) described the application of microcontact printing techniques to create cell-adhesive patterns on surfaces; D.J. Irvine (MIT) reported on comb polymers that cluster adhesion peptides on $\mathrm{nm}$ scales to tune cell adhesive response. As a twist on this theme, G. Lemieux (UC-Berkeley) discussed the modification of cell surface glycoconjugates via carbohydrate metabolic pathways. Other participants reported exciting progress in surface-directed therapies. A.E. Barron (Northwestern Univ.) discussed progress in the synthesis of a novel class of lung surfactants to prevent lung collapse in prematurely born infants; M. Vacanti (Univ. of Massachusetts Medical School) reported the generation of spinal cord tissue in adult rats and partial recovery of motor function from neural progenitor cells seeded on a polymer composite scaffold.

Symposium Support: Pall Corp., Petroleum Research Fund, and Whitaker Foundation.

\section{Natural Length Scales of Polymers Used to Create Heterophase Structures}

The theme of Symposium EE on Nanostructures in Polymers revolved around showing how ways to exploit the natural length scales of polymeric materials to create heterophase structures of nanoscale dimensions. The systems discussed included organic/inorganic composites, block copolymers, polymer liquid crystals, and dendrimers. The Symposium began with an invited lecture by B.F. Chmelka (UCSanta Barbara) who showed how amphiphilic block copolymers, in combination with sol-gel chemistry methods, can be used to prepare polymer/ inorganic oxide systems with high degrees of nano/mesoscopic ordering over macroscopic dimensions. M.F. Rubner (MIT) demonstrated a novel layer-by-layer deposition strategy for producing nanoscopic, multilayered heterostructures containing metal nanoparticles. L. Leibler (Elf Atochem, France) discussed a unique method that involved exploiting the inherent self-assembling properties of triblock copolymers to produce supertough semicrystalline materials. Here, the nanoscopic domains of a glassy polymer, encapsulated within a rubbery material, embedded in a semicrystalline polymer matrix, produced toughness that could not be achieved by any other means. V.M. Rotello (Univ. of Massachusetts) showed how recognition sites randomly located along a polymer chain interacting with receptor sites, anchored on nanoparticles of gold, produced macroscopic assemblies of the nanoparticles, have welldefined sizes. This approach represents a novel means of addressing more complex recognition processes found in many biological systems.

C.J. Hawker (IBM) discussed chemical routes for preparation of dendritic and hyperbranched macromolecules. While different applications were discussed, a unique approach for preparing nanoporous films, of particular importance for low-dielectric constant insulators for microelectronic applications, was present- 
ed. E.J. Amis (NIST) continued the discussion of dendritic macromolecules with one of the most comprehensive treatments of the field. A clear picture of the structure of these polymeric nanoparticles emerged with the surprising result that the simplistic diagrams often shown for these molecules is not far from the truth. The Symposium then shifted to multicomponent polymeric and block copolymeric systems with the lecture of F.S. Bates (Univ. of Minnesota) who presented a definitive study on the response of pentablock copolymers to applied shear. The multiblock nature of the pentablock copolymer gives rise to relaxation pheomena that are unique to these materials and directly related to the trajectory of the copolymer in the microdomain morphology. T. ThurnAlbrecht (Univ. of Massachusetts) and H.M. Jaeger (Univ. of Chicago) presented results on the control and manipulation of the microdomain structure of copolymers in thin films using external fields. The nanodomain morphology was subsequently used as a heterogeneous substrate for metal evaporation, or as templates, to prepare well-defined metal nanowires. A.J. Liu (UCLA) discussed the use of phase separation and liquid crystalline order to generate novel blend morphologies for liquid crystal display technologies. J.T. Koberstein (Columbia Univ.), by comparing experimental observations of the surface segregation in miscible blends, concluded that compressibility plays a crucial role in the preferential segregation of components to a free surface. Theoretical treatments using a compressible lattice fluid theory, rather than mean-field arguments, were found to best describe the results. The sessions were also marked by numerous contributed presentations describing current synthetic, physical and self-assembly issues for producing nanomaterials based on polymers.

\section{Interfacial Properties of Polymers Explored}

(See MRS Proceedings Volume 629)

Symposium FF on Interfaces, Adhesion, and Processing in Polymer Systems focused on both the fundamental scientific aspects and the advances in applications of polymers at surfaces/interfaces/thin films and the effects of the interfaces on processing and adhesion. The demands placed upon polymer performance have driven the development of multicomponent polymer formulations with superior physical, mechanical, and interfacial properties. Many applications also require that a polymeric material be attached or placed in contact with another material. In certain cases, like the classic nonstick pan, lubrication, and release paper, it is desirable to create surfaces that do not interact with the material in contact. However, in applications such as rubber toughening of blends, filled or fiber-reinforced polymers, and coatings, dissimilar materials must adhere to each other for enhanced performance. Likewise, the structure and properties of polymer/metal interfaces play a crucial role in the shear field affecting the stickslip behavior during polymer processing, whereas biomaterial/biological interfaces play a key role in promising areas of biotechnology.

More specifically, sessions were organized on the structure and dynamics in thin films; on the structure and properties of polymer/polymer and polymer/wall interfaces; on the effect of polymeric interfaces on processing, friction, and lubrication; on the behavior of polyelectrolytes and proteins at surfaces as well as on the mechanical aspects of soft biomaterial interfaces (jointly with Symposium DD); on the formation of nanostructures in thin films and in the bulk (jointly with Symposium EE); on adhesion and its relation on interfacial structure; and on polymer surface modification.

Symposium Support: NSF.

\section{When the Material World Fails}

\section{(See MRS Proceedings Volume 630)}

Symposium GG, When Materials Matter: Analyzing, Predicting, and Preventing Disasters, brought together specialists from many areas to share perspectives on how the design and analysis of materials impacts catastrophes with human consequences. Subjects included aerospace fractures; heart valve failures; origins and prevention of fire; radiation damage; creep fracture; collapse of buildings; natural catastrophes such as earthquakes, snow avalanches, and hurricanes; weapons safety; nondestructuve body immobilization; and safety in routine, hazardous, and malevolent environments.

The topic of life-cycle engineering for materials had been covered before at MRS meetings, although not so broadly, and without the focus in this session on the relation between materials, disasters, and prevention. As the session unfolded, it became clear that determining responsibility in the wake of a major disaster can employ the broad range of tools and expertise that materials science has to offer. Speakers had been involved in Congressional testimony and as expert witnesses in numerous lawsuits.

The Symposium covered a diverse collection of technical fields. For example, studying environmental effects on construction materials requires thinking about long-term effects of changing temperature and humidity, as well as catastrophic storms. The safety of buildings involved issues of long-term degradation as well as extreme environments or hostile attacks.

A theme running through the Symposium was a set of challenges to the materials community. Speakers identified materials problems that could help prevent the disasters described in the talks. New forms of glass that disintegrate rather than shattering, and concrete with increased ductility were among the wishes.

Syposium Support: AFOSR, ARO, and SNL.

\section{Education Issues Addressed for the New Millennium}

Symposium $\mathrm{HH}$, Materials Science and Engineering Education in the New Millennium, addressed some of the key issues facing engineering educators and MSE curricula, with a special focus on undergraduate MSE education. In one session, the Symposium examined MSE programs from a curricular point-ofview. Topics ranged from specific questions of content to how programs are organized in other parts of the world.

Another topic examined the teaching that researchers do in the context of the many other duties of a faculty member. Presentations illustrated how teaching quality is considered as part of tenure decisions, how faculty can encourage collaborative learning, and how faculty members can improve their teaching skills, as is practiced at a number of institutions.

One session addressed the assessment of student learning, exploring group learning and how to write effective learning objectives for a course. Other sessions covered the use of the Internet and multimedia and laboratories and courses for non-MSE students.

Nobel Laureate L.M. Lederman (Illinois Mathematics and Science Academy), in a joint session with Symposium X, discussed how high school education could be dramatically improved by simply reversing the normal biology, then chemistry, then physics sequence. Another special part of the Symposium was the poster presentation by grant recipients of the MRS Undergraduate Materials Research Initiative (UMRI).

Symposium Support: NSF.

M|RIS 